Article

\title{
Experimental Study of Helical Shape Memory Alloy Actuators: Effects of Design and Operating Parameters on Thermal Transients and Stroke
}

\author{
Shane J. Yates and Alexander L. Kalamkarov* \\ Department of Mechanical Engineering, Dalhousie University, PO Box 15000, Halifax, Nova Scotia, \\ B3H 4R2, Canada; E-Mail: sjyates@dal.ca
}

* Author to whom correspondence should be addressed; E-Mail: alex.kalamkarov@dal.ca; Tel.: +1-902-494-6072; Fax: +1-902-423-6711.

Received: 22 December 2012; in revised form: 3 February 2013 / Accepted: 5 February 2013 / Published: 18 February 2013

\begin{abstract}
Shape memory alloy actuators' strokes can be increased at the expense of recovery force via heat treatment to form compressed springs in their heat-activated, austenitic state. Although there are models to explain their behaviour, few investigations present experimental results for support or validation. The aim of the present paper is to determine via experimentation how certain parameters affect a helical shape memory alloy actuator's outputs: its transformation times and stroke. These parameters include wire diameter, spring diameter, transition temperature, number of active turns, bias force and direct current magnitude. Six investigations were performed: one for each parameter manipulation. For repeatability and to observe thermo-mechanical training effects, the springs were cyclically activated. The resultant patterns were compared with results predicted from one-dimensional models to elucidate the findings. Generally, it was observed that the transformation times and strokes converged at changing stress levels; the convergence is likely the peak where the summation of elastic stroke and transformation stroke has reached its maximum. During cyclic loading, the actuators' strokes decreased to a converged value, particularly at larger internal stresses; training should therefore be performed prior to the actuator's implementation for continual use applications.
\end{abstract}

Keywords: shape memory alloys; helical shape memory alloy actuators; reaction times; strokes; electrical resistive heating; cyclic loading 


\section{Introduction}

Shape memory alloys (SMAs) got their name from their intrinsic ability to remember their shape. Using heat treatment techniques, a SMA actuator can be programmed to be a specific shape in its heat activated austenite phase; some shapes are more useful than others to perform mechanical work. Popular shapes used for mechanical mechanisms include wires, bars, torsion springs, helical springs and, more recently, wave springs [1]. SMAs in wire form are most popular, as they are readily available, low cost and generally less difficult to model. SMA wires also provide the highest recovery force, but unfortunately, have a low stroke; the recovery strain is typically less than $5 \%$. The limited stroke can be improved by using mechanical amplification mechanisms, such as levers or adjusting curvature, as was done in Phillip Beezley's Hylozoic Ground [2], but the mechanisms may require significant space along with a sacrifice in recovery force. Additionally, even with mechanical amplification, a great length of wire is needed for adequate stroke magnitudes. Sufficient space must therefore be provided for both the length of wire and the amplification mechanism.

One option to amplify the stroke is to shape a set SMA wire into compressed helical springs. These springs can be made using straight wire with heat treatment techniques and do not require any amplification mechanisms, but as the internal stress is caused via torsional loading rather than axial loading, the stress is concentrated at the wire's perimeter, rather than being evenly distributed along the wire's cross-section. The recovery force decreases as a result. Furthermore, the dynamic response and energy efficiency is worsened, mainly due to the power exploitation, under torsional loading, of the material in the center of the solid section, which adds to the cooling time and to the power consumption without contributing to the strength [3]. Despite their drawbacks, helical SMA actuators have been shown to be reliable mechanical actuators, provided that the load is not substantial.

Although there have been numerous studies on the dynamic response of helical SMA actuators (see [4-15]), their mechanical behaviour is yet to be completely understood. Additionally, most of these studies involve using as-drawn SMA wire to be heat treated into a spring; as-drawn SMA wire is not as readily available than annealed SMA wire and is generally more costly. Unlike as-drawn SMA wire, annealed SMA wire has already been through the final annealing process. Putting the wire through another annealing process could permit further diffusion and/or precipitation of $\mathrm{Ni}$ and $\mathrm{Ti}$ atoms to form precipitates, such as $\mathrm{Ni}_{14} \mathrm{Ti}_{11}$ at intermediate annealing temperatures (around $450{ }^{\circ} \mathrm{C}$ ) or $\mathrm{Ni}_{3} \mathrm{Ti}_{2}$ at higher temperatures (around $575{ }^{\circ} \mathrm{C}$ ) [16]. In both cases, the transition temperatures can increase due to the overall decrease in nickel atomic percentage [16,17]. Moreover, putting an alloy through an additional annealing process could lead to an increased permanent set, as well as a decrease in ultimate tensile stress, upper plateau stress and lower plateau stress [16-18]: undesirable properties for maximizing stroke and recovery force. Despite the warnings from the literature, annealed SMA wires were shape set into a compressed helical spring (i.e., springs with an initial pitch angle of approximately $0^{\circ}$ ) and were successfully installed on a reactive stage set to move textile flaps (see [19] and [20]). Testing the shape-set helical SMA actuators at different parameters for the stage set revealed that several parameters affected their reaction. Said revelations included a larger recovery force for smaller spring diameters, longer cooling and heating times for larger wire diameters and that a sufficient force is needed to extend the spring when cooled, but if too large, the spring failed to compress when heated. 
Although there are dynamic models in the literature to explain a helical SMA actuator's behaviour, there are few publications that present experimental results with these models for validation. Additionally, studies with experimental support generally do not stress the material past its upper plateau stress (such as [14] and [21]), as stress-induced martensite (SIM) would be prone to form, thus adding further complexity to predictive models. Although limiting the maximum shear stress to its elastic region is simpler to model and would enhance the actuator's fatigue life, the actuator's stroke is limited to the change in modulus of rigidity between phase transformations; the actuator would not transform from the de-twinning of martensite, a feature that could add up to 5\% transformation strain. Although one can use hard stops to prevent a SMA spring from reaching its upper plateau stress [22], they are additional components that may interfere with the actuator's dynamics; this component would not be necessary if SMA spring mechanics were completely understood.

The aim of the present study is to determine via experimentation how certain parameters affect a helical SMA actuator's performance. There are three main objectives in this investigation. The first is to find correlations between the parameters of a helical SMA actuator and its resultant dynamic response. As mentioned, models exist to predict their behaviour, but this investigation does not aim to validate or discredit these models for the following reasons:

- Some of the necessary material properties, such as recoverable shear strain, stress influence coefficients and upper plateau stress were not available from the manufacturer.

- The additional heat treatment may have altered some of the material properties, including the plateau stresses, permanent set and transition temperatures.

- The spring diameters were not measured during the transformations; one, therefore, cannot determine the true effective diameter when the actuator is fully extended when cooled.

This investigation focused on how the helical SMAs performance-namely the actuator's heating time, cooling time and stroke - are affected by certain parameters. These parameters include geometry parameters, such as the wire diameter, spring diameter and number of active turns; input parameters, such as the direct current and bias force magnitudes; and a parameter exclusive to SMAs - the transition temperature. Although deriving accurate models was outside the scope of this investigation, simplified behavioural models were used in this investigation to elucidate the findings and make sense of the experimental results. For the reaction times, the simplified models were derived using heat transfer equations retrofitted with SMA theory. For the strokes, four models were found in the literature.

The literature has shown that SMAs can undergo permanent deformation when thermally actuated over multiple cycles, especially when stressed past their upper plateau stress [12,18,23]. As a second objective, the study also investigated how each actuator's strokes and reaction times are affected under cyclic thermal loading. Research has shown that the transformation strain is greatest during the first transformation and gradually decreases to a constant transformation strain after a sufficient amount of thermal cycles [12,18,23]. Studies have shown that in SMA actuators for multiple use, lower transformation strains (i.e., lower loads) are more desirable, as they increase fatigue life and decrease plastic strain $[12,23]$. This study investigated the effects of cyclic loading to determine if similar patterns occurred. 
The third objective in this investigation is to simply catalogue the stroke and reaction times at different spring parameters. The catalogue can be used for reference in future projects that require specific stroke and reaction times.

\section{Helical SMA Actuator Behaviour and Dynamic Outputs}

As discussed, obtaining accurate models to characterize the experimental results was outside the scope of this study. However, behavioural models were found or derived to elucidate the findings. These models are presented in this section.

\subsection{Reaction Times}

If the SMA is in wire form, electrical activation is highly favoured, as it can be directly controlled, is instantaneous and relatively simple to implement. The electric current can be direct, alternating or pulse-width modulated. Direct current was used to activate the SMA springs in this investigation. Using electrically resistive heat transfer relationships of a cylindrical medium with constant electrical resistance, the elapsed time for an electrically resistive wire to heat from an initial temperature, $\mathrm{T}_{1}$, to final temperature, $\mathrm{T}_{2}$, may be modeled as Equation 1, which was derived using the heat transfer theorem [19]. $\rho, c, d$ and $R_{\mathrm{e}}$ ', respectively, represent a conductive wire's density, specific heat capacity, wire diameter and resistance per unit length, while $h, I$ and $T_{\infty}$, respectively, represent the convection coefficient, direct current magnitude and ambient temperature:

$$
\Delta t=\frac{-\rho c d}{4 h} \ln \frac{\left[T_{2}-\left(\frac{I^{2} R_{e}{ }^{\prime}}{\pi d h}+T_{\infty}\right)\right]}{\left[T_{1}-\left(\frac{I^{2} R_{e}{ }^{\prime}}{\pi d h}+T_{\infty}\right)\right]}
$$

A SMA goes through a phase change during a transformation: a phenomenon that not only absorbs or releases energy, but can also change its specific heat capacity and electrical resistivity. Reynaerts and Van Brussel [24] argued that the averaged specific heat capacity during a transformation would be the averaged value of the martensite specific heat capacity, $c_{\mathrm{M}}$, and austenite specific heat capacity, $c_{\mathrm{A}}$, plus the transformation enthalpy divided by the temperature interval for the respective transformation. The specific heat capacities for the martensite-to-austenite (MA) transformation, $c_{\mathrm{MA}}$, and austenite-to-martensite (AM) transformation, $c_{\mathrm{AM}}$, could therefore be modeled as Equations 2 and 3, respectively, where $X_{\mathrm{MA}}$ and $X_{\mathrm{AM}}$ represent the heat absorbed during the MA and AM transformations, respectively:

$$
\begin{gathered}
c_{\mathrm{MA}}=\frac{c_{\mathrm{A}}+c_{\mathrm{M}}}{2}+\frac{X_{\mathrm{MA}}}{A_{\mathrm{f}}-A_{\mathrm{s}}} \\
c_{\mathrm{AM}}=\frac{c_{\mathrm{A}}+c_{\mathrm{M}}}{2}+\frac{X_{\mathrm{AM}}}{M_{\mathrm{s}}-M_{\mathrm{f}}}
\end{gathered}
$$

As the MA and AM transformations are endothermic and exothermic, respectively, $\mathrm{X}_{\mathrm{MA}}$ and $\mathrm{X}_{\mathrm{AM}}$, respectively, have positive and negative values. $A_{\mathrm{s}}$ and $A_{\mathrm{f}}$, respectively, represent the temperatures at which the MA transformation begins and finishes; $M_{\mathrm{s}}$ and $M_{\mathrm{f}}$, respectively, represent the temperatures 
at which the AM transformation begins and finishes. By substituting Equation 2 or 3 into Equation 1 and assuming an electrical resistivity that is averaged between the martensite and austenite electrical resistivities (i.e., $\rho_{\mathrm{M}}$ and $\rho_{\mathrm{A}}$, respectively), one may solve for the transformation's reaction time. For a MA transformation, where $T_{1}=A_{\mathrm{s}}$ and $T_{2}=A_{\mathrm{f}}$, the time interval, $\Delta t_{\mathrm{MA}}$, may be presented as:

$$
\Delta t_{M A}=\frac{-\left(\rho_{\mathrm{M}}+\rho_{\mathrm{A}}\right) c_{\mathrm{MA}} d}{8 h} \ln \frac{\left[A_{\mathrm{f}}-\left(\frac{I^{2} R_{e}{ }^{\prime}}{\pi d h}+T_{\infty}\right)\right]}{\left[A_{\mathrm{s}}-\left(\frac{I^{2} R_{e}{ }^{\prime}}{\pi d h}+T_{\infty}\right)\right]}
$$

For the AM transformation, where $T_{1}=M_{\mathrm{s}}, T_{2}=M_{\mathrm{f}}$ and $I=0$, the time interval, $\Delta t_{\mathrm{AM}}$, may be presented as:

$$
\Delta t_{A M}=\frac{-\left(\rho_{\mathrm{M}}+\rho_{\mathrm{A}}\right) c_{\mathrm{AM}} d}{8 h} \ln \frac{\left[M_{\mathrm{f}}-T_{\infty}\right]}{\left[M_{\mathrm{s}}-T_{\infty}\right]}
$$

It must be noted that Equations 4 and 5 assume there is no stress load; the equations, therefore, disregard any superelastic effects. When stress is applied to a SMA, the transformation temperatures linearly increase. In the event that the alloy is subjected to a stress load, the stress-induced transition temperatures need to be calculated and substituted into Equations 4 and 5. Performing the substitutions, when the SMA is subjected to an axial stress load, $\sigma$, the resultant time intervals when accounting for superelasticity may be modeled as the first portion of Equations 6 and 7, where $C^{\mathrm{M}}$ and $C^{\mathrm{A}}$ represent the martensite and austenite stress influence coefficients, respectively:

$$
\begin{gathered}
\Delta t_{M A, \sigma}=\frac{-\rho c_{M A} d}{4 h} \ln \frac{\left[A_{\mathrm{f}}+\frac{\sigma}{C^{A}}-\left(\frac{I^{2} R_{e}{ }^{\prime}}{\pi d h}+T_{\infty}\right)\right]}{\left[A_{s}+\frac{\sigma}{C^{A}}-\left(\frac{I^{2} R_{e}{ }^{\prime}}{\pi d h}+T_{\infty}\right)\right]} \\
\Delta t_{A M, \sigma}=\Delta t_{A M, \sigma}=\frac{-\rho c_{\mathrm{AM}} d}{4 h} \ln \frac{\left[M_{\mathrm{f}}+\frac{\sigma}{C^{\mathrm{M}}}-T_{\infty}\right]}{\left[M_{\mathrm{s}}+\frac{\sigma}{C^{\mathrm{M}}}-T_{\infty}\right]}
\end{gathered}
$$

Equations 6 and 7 would be generally applicable to straight SMA wire, however, SMA springs have different stress distributions. At low deflections, the shear stress is due to direct and torsional shear, but predominantly torsional shear. Additionally, when SIM forms during its austenite phase or when martensitic de-twinning occurs, an SMA spring's internal stress has been shown to be non-linear [13,14,22,25], as opposed to the linear torsional shear stress observed in isotropic springs. Although Liang and Rogers developed a constitutive model for a spring that substituted the applied axial stress with the von Mises criterion under pure shear, i.e., $\sigma=\tau \sqrt{3}$ [7], this cannot be directly substituted into Equations 6 and 7, as the internal stress is not constant throughout the SMA wire. It should also be noted that Equations 6 and 7 do not take into account the work performed by the spring during a transformation. Regardless, Equations 6 and 7 show that internal stress does affect the SMAs transformation times and will be used to elucidate the experimental results. 


\subsection{Stroke}

During the study's preparation, several one-dimensional models were found in the literature to predict a SMA spring's stroke. Although none would be directly compared to the experimental results, as none effectively modeled the change in spring diameter and pitch angle, each model provided insight to elucidating the experimental findings.

\subsubsection{Elastic Stroke Model}

Using traditional spring mechanics and solely accounting for the change in modulus of rigidity, the elastic stroke model predicts a stroke, $\Delta \delta_{\mathrm{MA}}$, equivalent to the difference between the martensite and austenite deflections, $\delta_{\mathrm{M}}$ and $\delta_{\mathrm{A}}$ :

$$
\Delta \delta_{\mathrm{MA}}=\delta_{\mathrm{M}}-\delta_{\mathrm{A}}=F \frac{8 D_{m}^{3} N}{d^{4}}\left(\frac{1}{G_{\mathrm{M}}}-\frac{1}{G_{\mathrm{A}}}\right)=F \frac{8 D_{m}^{3} N\left(G_{\mathrm{A}}-G_{\mathrm{M}}\right)}{d^{4} G_{\mathrm{M}} G_{\mathrm{A}}}
$$

where $F, D_{\mathrm{m}}, N, G_{\mathrm{M}}$ and $G_{\mathrm{A}}$ represent the bias force, spring diameter, number of active turns, martensite modulus of rigidity and austenite modulus of rigidity, respectively. Although some articles, such as [26], state that Equation 8 can be used to calculate the overall stroke, it is generally disputed in the literature, as it disregards the de-twinning of martensite when cooled. Although fair to assume to be negligible, Equation 8 also fails to account for thermal strains. However, providing that the deformation is small enough to not affect the actuator's spring diameter and that the applied stress is below the critical stress needed to de-twin martensite, Equation 8 may be used to model the actuator's stroke.

\subsubsection{Constitutive Model}

Unlike straight wire, helical springs are usually modeled with reference to their internal shear stress, $\tau$, and shear strain, $\gamma$. Based on the multidimensional constitutive relations, Liang \& Rogers presented the differential and integrated constitutive equations of a nitinol spring as Equations 9 and 10; the equations are based on the von Mises criterion of a body experiencing pure shear [7]. As shown in Equation 11, G represents the SMAs elastic shear modulus, which is an interpolation of the austenitic and martensite moduli of rigidity with respect to the martensite volume fraction, $\xi$ :

$$
\begin{gathered}
\mathrm{d} \tau=G \mathrm{~d} \gamma+\frac{\Omega}{\sqrt{3}} \mathrm{~d} \xi+\frac{\Theta}{\sqrt{3}} \mathrm{~d} T \\
\tau-\tau_{0}=G\left(\gamma-\gamma_{0}\right)+\frac{\Omega}{\sqrt{3}}\left(\xi-\xi_{0}\right)+\frac{\Theta}{\sqrt{3}}\left(T-T_{0}\right) \\
G=G^{A}+\xi\left(G^{\mathrm{M}}-G^{\mathrm{A}}\right)=\frac{D}{2\left\{1+\left[v^{\mathrm{A}}+\xi\left(v^{\mathrm{M}}-v^{\mathrm{A}}\right)\right]\right\}}
\end{gathered}
$$

The three tensors in Equations 9-11, D, $\theta$ and $\Omega$, are known as the stiffness, thermoelastic and transformation tensors, respectively. The stiffness and thermoelastic tensors are derived from traditional mechanics using the associated moduli of elasticity, coefficients of thermal expansion and martensite volume fraction. The transformation tensor is unique to SMAs. The transformation tensor accounts for the change in strain experienced during a phase transformation and how it affects the 
stress experienced by the SMA. The transformation tensor is modeled as Equation 12 , where $\mathrm{H}^{\text {cur }}(\sigma)$ is the maximum transformation strain at a specific stress:

$$
\Omega=-D H^{\text {cur }}(\sigma)
$$

Rearranging Equation 10 with initial conditions of stress, strain and martensite fraction to be 0 and assuming Wahl concentrations to be negligible, one can solve for the spring's maximum shear strain, $\gamma_{\max }$, which occurs at the perimeter of the wire's cross-section:

$$
\gamma_{\max }=\frac{\tau_{\max }}{G}-\frac{\Omega}{G \sqrt{3}} \xi-\frac{\Theta}{G \sqrt{3}} T
$$

Solving for the spring deflection, $\delta$, that experiences a shear strain of $\gamma_{\max }$ :

$$
\delta=\frac{\pi D_{m}^{2} N}{d} \gamma_{\max }=\frac{\pi D_{m}^{2} N}{d}\left(\frac{\tau_{\max }}{G}-\frac{\Omega}{G \sqrt{3}} \xi-\frac{\Theta}{G \sqrt{3}} T\right)=\frac{\pi D_{m}^{2} N}{d}\left(\frac{8 F D_{m}}{G \pi d^{3}}-\frac{\Omega}{G \sqrt{3}} \xi-\frac{\Theta}{G \sqrt{3}} T\right)
$$

Assuming a complete transformation with a negligible thermal stroke, the total stroke from a MA transformation, $\Delta \delta_{\mathrm{MA}}$, may be modeled as:

$$
\Delta \delta_{\mathrm{MA}}=\frac{\pi D_{m}^{2} N}{d}\left(\frac{8 F D_{m}}{\pi d^{3}} \frac{G_{\mathrm{A}}-G_{\mathrm{M}}}{G_{\mathrm{M}} G_{\mathrm{A}}}+\frac{2(1+v) H^{c u r}(\sigma)}{\sqrt{3}}\right)
$$

The total stroke is thus dependent on two terms: the elastic stroke (the left term in Equation 15) and the recovery stroke (the right term in Equation 15). Both terms add to the deflection, thus making the overall deflection larger than the elastic stroke term alone. However, the model does not take into account the decrease in spring diameter at large spring deformations nor permanent deformation if strained past the alloy's upper plateau stress.

\subsubsection{Effective Stroke Model}

All of the stroke formulas presented thus far assume that the spring diameter does not change during a phase transformation. This assumption is not realistic, as the de-twinning of martensite will encourage the spring diameter to decrease during an AM transformation. Kim et al. addressed this issue by presenting an effective stroke model [14]:

$$
\Delta \delta_{\mathrm{MA}}=\delta_{\mathrm{d}}+\delta_{\mathrm{L}}+\delta_{\mathrm{A}}=\frac{\pi \gamma_{\mathrm{d}} D_{m}^{2} N}{d}+\frac{8 F D_{e f f}^{3} N}{G_{\mathrm{M}} d^{4}}-\frac{8 F D_{m}^{3} N}{G_{\mathrm{A}} d^{4}}
$$

where $\delta_{\mathrm{d}}$ represents the deflection from de-twinning the martensite, $\delta_{\mathrm{L}}$ represents the elastic deflection of the de-twinned martensite and $\delta_{\mathrm{A}}$ represents the spring's elastic deflection during its austenite phase. For the $\delta_{\mathrm{d}}$ deflection term, $\gamma_{\mathrm{d}}$ represents the shear strain experienced by the spring during the de-twinning of martensite and is equivalent to the right most term in Equation 15. For the $\delta_{\mathrm{L}}$ deflection term, $D_{\text {eff }}$ represents the effective spring diameter after it has been reduced by the de-twinning of martensite. However, Equation 16 fails to take account of the change in spring diameter during the de-twinning of martensite. In addition, Kim et al. went on to model the effective diameter as:

$$
D_{\text {eff }}=D_{m} \cos \alpha
$$

where $\alpha$ represents the pitch angle. The relationship dictated by Equation 17 assumes a relatively small pitch angle, where the spring's vertical contour resembles a zigzag. At larger pitch angles (and strokes), the spring's outline becomes more sinusoidal in appearance, and the effective diameter can no longer be determined by the pitch angle alone. Equation 16 also fails to take into account the bending moment that becomes apparent at larger deformations and pitch angles. 


\subsubsection{Static Two-State Model}

To account for the bending moment at larger strokes, An et al. devised a "static two-state model" [6]. As part of the static two-state model, the total stroke was modeled as:

$$
\delta=D_{\gamma}^{3} n\left(\frac{8 F}{G_{\mathrm{M}} d^{4}}+\frac{\pi}{d D_{\mathrm{A}}} \gamma_{\mathrm{L}} \xi_{\mathrm{ST}}\right) \cos ^{-3} \alpha_{i} \cos ^{2} \alpha_{f}\left(\cos ^{2} \alpha_{f}+\sin ^{2} \alpha_{f} /\left(1+v_{\mathrm{M}}\right)\right)
$$

where $\gamma_{\mathrm{L}}, \mathrm{D}_{\mathrm{A}}, \mathrm{D}_{\gamma}, \xi_{\mathrm{ST}}, \alpha_{i}$ and $\alpha_{f}$ represent maximum recoverable shear strain, the spring diameter in the austenite phase, the spring diameter once the maximum recoverable shear strain has been realized, the de-twinned martensite volume fraction, the pitch angle once the maximum recoverable shear strain has been realized and the final pitch diameter. Although this model takes account of bending stresses only seen in larger deformations, like the effective stroke model developed by Kim et al., the static two-state model does not take into account the change in diameter during the de-twinning of martensite. Likewise, the static two-state model assumes a relatively small change in pitch angle so that the spring's vertical contour resembles a zigzag pattern, as opposed to the sinusoidal pattern that is observed at larger deformations. Although An et al. performed an experimental trial to validate their static two-state model, they did not strain the spring past its maximum recoverable shear strain to avoid permanent deformation. The model is, therefore, limited to its maximum recoverable shear strain.

\section{Experimental Analysis}

For repeatability, at least three trials (one trial being one individual spring) were performed for each investigation, and every SMA spring was activated on and off for 20 cycles. Only one variable would be manipulated at one time, while the remaining variables would be controlled. Each experiment was set up to be compared in relation to a helical SMA actuator with a $0.25 \mathrm{~mm}$ wire diameter, a $3.175 \mathrm{~mm}$ spring diameter, a $70{ }^{\circ} \mathrm{C}$ transition temperature and 16 active spring turns carrying a bias mass of $30 \mathrm{~g}$ and activated with a $0.55 \mathrm{~A}$ direct current. This experimental plan was chosen to enable one to observe how differing a single variable affects the actuator's dynamic output.

A summary of the manipulated and controlled properties for all 6 experiments is presented as Table 1, where each vertical column in the "Manipulated Variable Experiments" section represents one investigation. The manipulated variable is each investigation's title, and the magnitudes of the manipulated variable are presented where the manipulated variable and parameter values meet; the controlled values for the remaining parameters are listed in the remaining rows. For example, for the wire diameter manipulation, wire diameters of $0.15 \mathrm{~mm}, 0.20 \mathrm{~mm}, 0.25 \mathrm{~mm}$ and $0.38 \mathrm{~mm}$ were investigated with an inner spring diameter of $3.175 \mathrm{~mm}$, an austenite starting temperature of $70{ }^{\circ} \mathrm{C}$, 16 active turns, bias masses of $30 \mathrm{~g}$ (i.e., bias forces of $0.294 \mathrm{~N}$ ) and direct currents of $0.55 \mathrm{~A}$. With at least three trials for each wire diameter, a minimum of 12 total springs were tested in this investigation.

Before carrying out the experiments, the heating and cooling reaction times were calculated using Equations 4 and 5. To see if an improvement on the reaction times could be obtained when accounting for superelasticity, the heat and cooling reaction times were also calculated using

Equations 6 and 7, substituting $\sigma$ with $\tau_{\max } \sqrt{3}$. These calculations were only performed to provide a pattern of heating times and cooling times with respect to an increasing manipulated variable parameter to elucidate the experimental findings. The convection coefficient and ambient room 
temperature were assumed constant at $15 \mathrm{~W} / \mathrm{m}^{2}$ and $15{ }^{\circ} \mathrm{C}$, respectively. Using a scale with a $0.1 \mathrm{~g}$ resolution, all bias masses were weighed and were accurate to their manufactured specifications. The wire diameters and inner spring diameters (i.e., steel rod diameters) were measured using a micrometer with $1.27 \times 10^{-6} \mathrm{~m}$ resolution. The material properties used in these calculations were found from the manufacturer, Dynalloy, Inc., and are listed in Table 2. However, as An et al. [14] used the same commercial nitinol springs as were used in this investigation and they performed tensile testing of springs to obtain material properties that catered to spring calculations, these properties were also used in the pre-emptive calculations. The material properties used in this investigation are listed in Table 2.

Table 1. The manipulated and controlled properties for all manipulated variable experiments.

\begin{tabular}{|c|c|c|c|c|c|c|c|}
\hline \multirow[b]{2}{*}{ Parameter values } & \multirow[b]{2}{*}{ Units } & \multicolumn{6}{|c|}{ Manipulated Variable Experiments } \\
\hline & & $\begin{array}{c}\text { Wire } \\
\text { diameter }\end{array}$ & $\begin{array}{l}\text { Inner spring } \\
\text { diameter }\end{array}$ & $\begin{array}{l}\text { Bias } \\
\text { mass }\end{array}$ & $\begin{array}{c}\text { Number } \\
\text { of spring } \\
\text { turns }\end{array}$ & $\begin{array}{l}\text { Direct } \\
\text { current }\end{array}$ & $\begin{array}{c}\text { Transition } \\
\text { temperature }\end{array}$ \\
\hline Wire Diameter & $\mathrm{mm}$ & $\begin{array}{c}0.15,0.20 \\
0.25,0.38\end{array}$ & 0.25 & 0.25 & 0.25 & 0.25 & 0.25 \\
\hline Inner Spring Diameter & $\mathrm{mm}$ & 3.175 & $\begin{array}{c}2.38,3.175 \\
4.76,6.35\end{array}$ & 3.175 & 3.175 & 3.175 & 3.175 \\
\hline Bias Mass & g & 30 & 30 & $\begin{array}{c}20,30 \\
40,50\end{array}$ & 30 & 30 & 30 \\
\hline Number of Active Turns & - & 16 & 16 & 16 & $\begin{array}{c}8,12,16 \\
20\end{array}$ & 16 & 16 \\
\hline Direct Current & A & 0.55 & 0.55 & 0.55 & 0.55 & $\begin{array}{l}0.45,0.5 \\
0.55,0.6\end{array}$ & 0.55 \\
\hline Transition Temperature & ${ }^{\circ} \mathrm{C}$ & 70 & 70 & 70 & 70 & 70 & 70,90 \\
\hline
\end{tabular}

As an appropriate one-dimensional stroke model was not found in the literature or realized, the experimental strokes would not be directly compared to a predictive model. Alternatively, the stroke models presented in Section 2.2 would be used to explain the experimental stroke patterns pertaining to each manipulated variable investigation.

The SMA springs were shape set by wrapping the SMA wire around a steel rod to form a compressed spring. The wire was then constrained using clamps and subsequently heated. From the literature, the necessary heat times and temperatures were estimated at $10 \mathrm{~min}$ and $500{ }^{\circ} \mathrm{C}$, as these settings have been shown to adequately shape set the alloy without significantly changing the material's transition temperature and strength properties [16-18,27]. Conversely, it should be noted that these parameters are not completely agreed upon in the literature [11]. To know for sure what heating times and temperatures are needed to minimize strength degradation and aging, one must determine them through experimentation; experimenting with the annealing temperature and time is outside the scope of this investigation. After removing the SMA springs after the allotted heat time, the springs were water quenched. After cutting the springs to their designated length, the wires were crimped to insulated electrical wires and later connected to the variable power source and transistor. The bias mass was attached to the SMA through wrapping excess insulated wire around the bias mass's neck and using adhesive to fasten the insulated wire to the center of the bias mass's top face; 
this ensured that the corresponding end of the insulated wire along with the bias mass were in line with the SMA spring to minimize connection eccentricities and resultant stress concentrations. It should be noted, however, that eccentricity was not entirely avoided, as the insulated wires were directly crimped to the SMA spring.

Table 2. The material properties of the shape memory alloy (SMA) wire and estimated material properties.

\begin{tabular}{|c|c|c|}
\hline Property & Value & Source \\
\hline Density, $\rho$ & $6.45 \mathrm{~g} / \mathrm{cm}^{3}$ & {$[28]$} \\
\hline Specific Heat, $c_{A}=c_{M}$ & $837.36 \mathrm{~J} / \mathrm{kg} / \mathrm{K}\left(0.2 \mathrm{cal} / \mathrm{g}^{* \circ} \mathrm{C}\right)$ & [28] \\
\hline Latent Heat of Transformation, $\mathrm{X}_{\mathrm{AM}}$ & $24,190.4 \mathrm{~J} / \mathrm{kg}(5.78 \mathrm{cal} / \mathrm{g})$ & [28] \\
\hline \multicolumn{3}{|l|}{ Electrical Resistivity } \\
\hline Austenite, $\rho_{\mathrm{A}}$ & \multirow{2}{*}{$\begin{array}{l}100 \text { micro-ohms*cm } \\
80 \text { micro-ohms* }{ }^{*} \mathrm{~cm}\end{array}$} & \multirow{3}{*}{ [28] } \\
\hline Martensite, $\rho_{M}$ & & \\
\hline Transition Temperatures & $90{ }^{\circ} \mathrm{C}$ Wire & \\
\hline $\mathrm{A}_{\mathrm{s}}$ & 70 & \\
\hline$A_{f}$ & 110 & [28] \\
\hline $\mathrm{M}_{\mathrm{s}}$ & 65 & \\
\hline $\mathrm{M}_{\mathrm{f}}$ & 45 & \\
\hline \multicolumn{3}{|l|}{ Modulus of Elasticity } \\
\hline Martensite, $\mathrm{E}_{\mathrm{M}}$ & $28 \mathrm{GPa}$ & [28] \\
\hline Austenite, $\mathrm{E}_{\mathrm{A}}$ & $83 \mathrm{GPa}$ & \\
\hline $\begin{array}{c}\text { Poisson's Ratio, } v \text { (Estimated from } \\
\text { the literature) }\end{array}$ & 0.3 & [23] \\
\hline \multicolumn{3}{|l|}{ Stress Influence Coefficients (Estimated } \\
\hline \multicolumn{2}{|l|}{ from the literature) } & \multirow{3}{*}{ [23] } \\
\hline $\mathrm{C}^{\mathrm{A}}$ & $7 \mathrm{MPa} /{ }^{\circ} \mathrm{C}$ & \\
\hline $\mathrm{C}^{\mathrm{M}}$ & $7 \mathrm{MPa} /{ }^{\circ} \mathrm{C}$ & \\
\hline \multicolumn{3}{|l|}{ Critical Shear Stresses } \\
\hline Start of Martensite De-twinning, $\tau_{s}^{c r}$ & 114.0 MPa & [14] \\
\hline End of Martensite De-twinning, $\tau_{f}^{c r}$ & $72.4 \mathrm{MPa}$ & [14] \\
\hline Upper Plateau Shear Stress, $\tau_{A}^{c r}$ & $183 \mathrm{MPa}$ & [14] \\
\hline Maximum Recoverable Shear Strain, $\gamma_{\mathrm{L}}$ & 0.05 & [14] \\
\hline
\end{tabular}

Figure 1 gives a sketch of the SMA spring/bias mass apparatus along with its main geometrical parameters. The overall testing apparatus is pictured in Figure 2, while Figure 3 gives a close-up of the electronic components (for an electronic schematic of the apparatus, refer to [19]). The apparatus was controlled using an Arduino duemilanove (2009) microprocessor. The power source had variable current settings, allowing the SMA wire to be activated using direct current of a constant magnitude. The direct current was turned on and off using the microprocessor and a transistor. To sense the position of the bias mass, an ultrasonic ranger was used. The code was written to detect when the bias mass was stationary, i.e., when a transformation has ended. When the microprocessor detected a stationary bias mass, its input to the transistor switched from high to low or vice versa. Originally, the ultrasonic ranger was meant to measure the austenite lengths, martensite lengths and strokes; however, 
the ultrasonic ranger tended to underestimate the strokes by up to $10 \mathrm{~mm}$. The austenite lengths, martensite lengths and strokes were therefore measured by the operator using a stationary ruler. The times between transitions (i.e., the reaction times) were measured and recorded by the microprocessor.

Figure 1. Sketch of the SMA spring setup, including dimensions and components. The sketched spring has nine active coils and one dead coil. Dimensions include the wire diameter $(d)$, inner spring diameter $\left(D_{\mathrm{i}}\right)$, mid spring diameter $\left(D_{\mathrm{m}}\right)$ and outer spring diameter $\left(D_{0}\right)$.

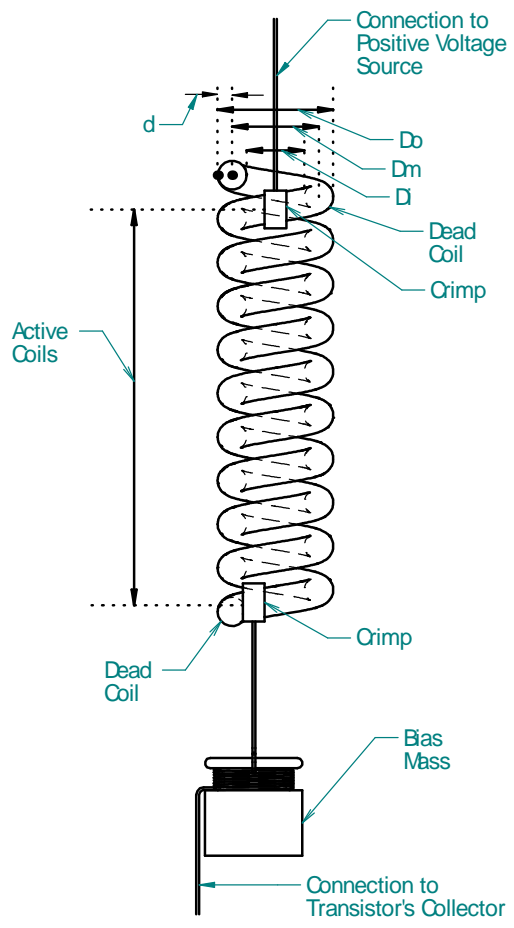

Figure 2. The labelled testing apparatus for the SMA helical spring experiments.

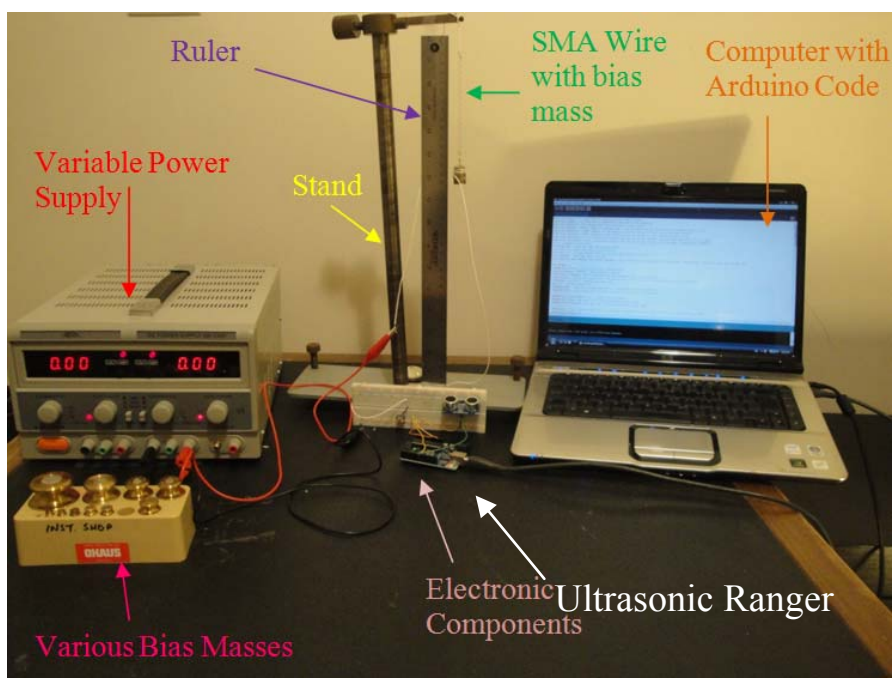


Figure 3. A close-up of the testing apparatus's electronic components.

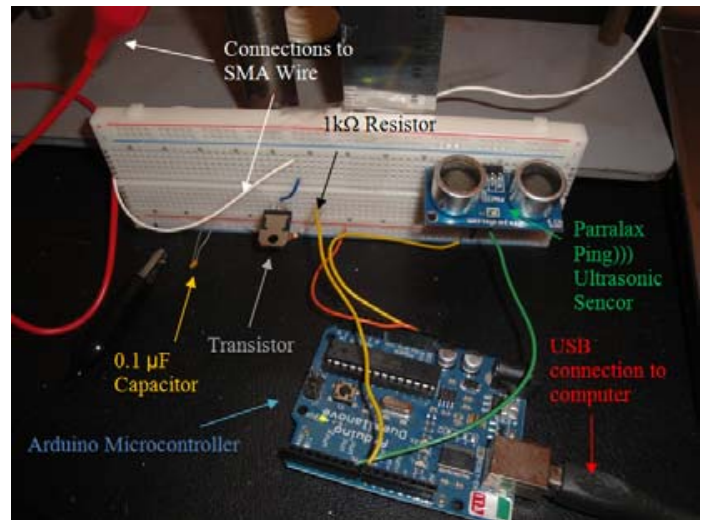

During a trial, the Arduino code was activated. The transistor's base was initially turned high, allowing direct current to activate a MA transformation in a SMA spring. Taking the data from the ultrasonic sensor, the microprocessor determined when the transformation is complete, upon which the microprocessor turned the transistor's base low, allowing the SMA wire to cool back to its martensite form. The microprocessor logged the elapsed time, i.e., the heating time. When the SMA wire finished its AM transformation as determined by the microprocessor, the transistor's base was turned to high, and the microprocessor logged the elapsed time, i.e., the cooling time. As mentioned, the martensite lengths, austenite lengths and strokes were measured using a stationary ruler by the operator. Each trial consisted of 20 cycles, giving 20 heating times, cooling times, martensite spring lengths, austenite spring lengths and stroke measurements. 20 cycles were performed not only for repeatability, but to also observe if the results changed after subsequent activation cycles due to training. If training is a factor, the stroke would be expected to be highest during the first activation and decreasing after each subsequent cycle, until the stroke converges to a set stroke.

For each trial, the mean, median and \%-standard deviation were obtained. To obtain the results for each setting as a whole, the results from the respective trials (at least three) were combined to get the averaged mean, averaged median and \%-pooled standard deviation. On some trials, a few heating and cooling times were observably shorter than what was recorded; these trials had larger standard deviations as a result. As these few outliers skewed the mean values, it was felt that the median values would better reflect the true reaction times. The averaged median values were thus used for further analysis and discussion along with the averaged values obtained from the first and last (i.e., 20th) actuations.

\section{Results and Discussion}

The experimental reaction times were compared to those calculated using Equations 4 to 7 to clarify the findings. The calculated values are presented in Table 3. For the equations accounting for superelasticity, i.e., Equations 6 and 7, the axial stress $(\sigma)$ was replaced with the von Mises equivalent of the spring's maximum shear stress (i.e., $\sigma=\tau_{\max } \sqrt{3}=8 \sqrt{3} F D_{m} /\left(\pi d^{3}\right)$ ). For the heating times, neither Equation 4 nor Equation 6 accurately predicted the reaction times; the calculations were generally underestimated by $70 \%$. However, Equation 6 did project the correct correlations between heat time and a manipulated parameter. Alternatively, for the cooling times, the calculations that 
included superelastic effects better correlated to the experimental cooling times. Without accounting for superelasticity (i.e., Equation 5) the cooling times were greatly overestimated, often having errors greater than $100 \%$. Alternatively, the cooling time formula that included superelasticity (i.e., Equation 7) often had calculated cooling times that were within $10 \%$ of the experimental cooling times. This result supports the notion that superelasticity cannot be ignored when calculating the reaction times. However, it should be reiterated that Equation 4 through Equation 7 were generalized equations that omitted several important parameters, including the work being done during a transformation, the change in spring diameter and substituting the axial stress with the maximum shear stress; the shear stress actually varies from zero at the wire's center and non-linearly increases to its maximum value at the wire's perimeter. Nonetheless, these equations gave insight towards explaining the experimental results.

Table 3. Calculated values using Equations 4-8.

\begin{tabular}{|c|c|c|c|c|c|c|}
\hline $\begin{array}{l}\text { Manipulate } \\
d \text { variable }\end{array}$ & Magnitude & $\begin{array}{c}\text { Calculated } \\
\text { heating time } \\
\text { without } \\
\text { accounting } \\
\text { for } \\
\text { superelasticit } \\
\text { y (i.e., } \\
\text { Equation 4) }\end{array}$ & $\begin{array}{c}\text { Calculated } \\
\text { heating time } \\
\text { accounting for } \\
\text { superelasticity } \\
\text { (i.e., } \\
\text { Equation 6) }\end{array}$ & $\begin{array}{c}\text { Calculated } \\
\text { cooling time } \\
\text { without } \\
\text { accounting for } \\
\text { superelasticity } \\
\text { (i.e., Equation 5) }\end{array}$ & $\begin{array}{c}\text { Calculated } \\
\text { cooling time } \\
\text { accounting } \\
\text { for } \\
\text { superelasticit } \\
\text { y (i.e., } \\
\text { Equation 7) }\end{array}$ & $\begin{array}{c}\text { Calculated } \\
\text { stroke using } \\
\text { the elastic } \\
\text { stroke model } \\
\text { (i.e., } \\
\text { Equation 8) }\end{array}$ \\
\hline \multirow{4}{*}{$\begin{array}{c}\text { Wire } \\
\text { Diameter }\end{array}$} & $0.145 \mathrm{~mm}$ & $0.54 \mathrm{~s}$ & $0.66 \mathrm{~s}$ & $16.2 \mathrm{~s}$ & $2.6 \mathrm{~s}$ & $198 \mathrm{~mm}$ \\
\hline & $0.192 \mathrm{~mm}$ & $0.98 \mathrm{~s}$ & $1.09 \mathrm{~s}$ & $21.6 \mathrm{~s}$ & $6.6 \mathrm{~s}$ & $66 \mathrm{~mm}$ \\
\hline & $0.248 \mathrm{~mm}$ & $1.68 \mathrm{~s}$ & $1.79 \mathrm{~s}$ & $27.9 \mathrm{~s}$ & $13.5 \mathrm{~s}$ & $25 \mathrm{~mm}$ \\
\hline & $0.375 \mathrm{~mm}$ & $4.02 \mathrm{~s}$ & $4.15 \mathrm{~s}$ & $42.1 \mathrm{~s}$ & $31.8 \mathrm{~s}$ & $5.4 \mathrm{~mm}$ \\
\hline \multirow{4}{*}{$\begin{array}{l}\text { Inner Spring } \\
\text { Diameter }\end{array}$} & $2.38 \mathrm{~mm}$ & $1.68 \mathrm{~s}$ & $1.76 \mathrm{~s}$ & $27.9 \mathrm{~s}$ & $15.4 \mathrm{~s}$ & $11 \mathrm{~mm}$ \\
\hline & $3.175 \mathrm{~mm}$ & $1.68 \mathrm{~s}$ & $1.79 \mathrm{~s}$ & $27.9 \mathrm{~s}$ & $13.5 \mathrm{~s}$ & $25 \mathrm{~mm}$ \\
\hline & $4.76 \mathrm{~mm}$ & $1.68 \mathrm{~s}$ & $1.85 \mathrm{~s}$ & $27.9 \mathrm{~s}$ & $10.9 \mathrm{~s}$ & $80 \mathrm{~mm}$ \\
\hline & $6.35 \mathrm{~mm}$ & $1.68 \mathrm{~s}$ & $1.91 \mathrm{~s}$ & $27.9 \mathrm{~s}$ & $9.1 \mathrm{~s}$ & $180 \mathrm{~mm}$ \\
\hline \multirow{4}{*}{$\begin{array}{c}\text { Bias } \\
\text { Mass/Bias } \\
\text { Force }\end{array}$} & $20 \mathrm{~g} / 0.196 \mathrm{~N}$ & $1.68 \mathrm{~s}$ & $1.75 \mathrm{~s}$ & $27.9 \mathrm{~s}$ & $16.3 \mathrm{~s}$ & $1.7 \mathrm{~mm}$ \\
\hline & $30 \mathrm{~g} / 0.294 \mathrm{~N}$ & $1.68 \mathrm{~s}$ & $1.79 \mathrm{~s}$ & $27.9 \mathrm{~s}$ & $13.5 \mathrm{~s}$ & $2.5 \mathrm{~mm}$ \\
\hline & $40 \mathrm{~g} / 0.392 \mathrm{~N}$ & $1.68 \mathrm{~s}$ & $1.83 \mathrm{~s}$ & $27.9 \mathrm{~s}$ & $11.5 \mathrm{~s}$ & $3.3 \mathrm{~mm}$ \\
\hline & $50 \mathrm{~g} / 0.490 \mathrm{~N}$ & $1.68 \mathrm{~s}$ & $1.87 \mathrm{~s}$ & $27.9 \mathrm{~s}$ & $10.1 \mathrm{~s}$ & $4.2 \mathrm{~mm}$ \\
\hline \multirow{4}{*}{$\begin{array}{c}\text { Number of } \\
\text { Turns }\end{array}$} & 8 & $1.68 \mathrm{~s}$ & $1.79 \mathrm{~s}$ & $27.9 \mathrm{~s}$ & $13.5 \mathrm{~s}$ & $1.2 \mathrm{~mm}$ \\
\hline & 12 & $1.68 \mathrm{~s}$ & $1.79 \mathrm{~s}$ & $27.9 \mathrm{~s}$ & $13.5 \mathrm{~s}$ & $1.9 \mathrm{~mm}$ \\
\hline & 16 & $1.68 \mathrm{~s}$ & $1.79 \mathrm{~s}$ & $27.9 \mathrm{~s}$ & $13.5 \mathrm{~s}$ & $2.5 \mathrm{~mm}$ \\
\hline & 20 & $1.68 \mathrm{~s}$ & $1.79 \mathrm{~s}$ & $27.9 \mathrm{~s}$ & $13.5 \mathrm{~s}$ & $3.1 \mathrm{~mm}$ \\
\hline \multirow{4}{*}{$\begin{array}{c}\text { Direct } \\
\text { Current }\end{array}$} & $0.45 \mathrm{~A}$ & $2.63 \mathrm{~s}$ & $2.93 \mathrm{~s}$ & $27.9 \mathrm{~s}$ & $13.5 \mathrm{~s}$ & $2.5 \mathrm{~mm}$ \\
\hline & $0.50 \mathrm{~A}$ & $2.07 \mathrm{~s}$ & $2.25 \mathrm{~s}$ & $27.9 \mathrm{~s}$ & $13.5 \mathrm{~s}$ & $2.5 \mathrm{~mm}$ \\
\hline & $0.55 \mathrm{~A}$ & $1.68 \mathrm{~s}$ & $1.79 \mathrm{~s}$ & $27.9 \mathrm{~s}$ & $13.5 \mathrm{~s}$ & $2.5 \mathrm{~mm}$ \\
\hline & $0.60 \mathrm{~A}$ & $1.39 \mathrm{~s}$ & $1.46 \mathrm{~s}$ & $27.9 \mathrm{~s}$ & $13.5 \mathrm{~s}$ & $2.5 \mathrm{~mm}$ \\
\hline Transition & $70^{\circ} \mathrm{C}$ & $1.68 \mathrm{~s}$ & $1.79 \mathrm{~s}$ & $27.9 \mathrm{~s}$ & $13.5 \mathrm{~s}$ & $2.5 \mathrm{~mm}$ \\
\hline Temperature & $90^{\circ} \mathrm{C}$ & $1.64 \mathrm{~s}$ & $1.76 \mathrm{~s}$ & $19.6 \mathrm{~s}$ & $10.8 \mathrm{~s}$ & $2.5 \mathrm{~mm}$ \\
\hline
\end{tabular}


For the experimental strokes, none of the results were directly compared with any of the one-dimensional models presented in Section 2.2, as they all had problems accounting for the change in spring diameter at large deformations, especially with deformations that strain the SMA spring past its maximum recoverable shear strain. To gain insight towards explaining the experimental results, the elastic stroke model (i.e., Equation 8) was used to calculate what the stroke would be if one only took account of the change in modulus of elasticity. These calculated elastic strokes are presented in Table 3. One continuing trend that occurred throughout the investigations was a convergence to a specific stroke value. This convergence was observed in manipulations that changed the internal stress, i.e., the bias force, wire diameter and spring diameter manipulations. It is believed that the convergence is actually a peak where the summation of the strokes due to martensitic de-twinning and change in modulus of rigidity has reached its maximum.

When comparing the averaged first, median and end strokes from each trial set, the averaged first strokes recorded during the first cycle were generally larger than the averaged median and end strokes. Additionally, the strokes recorded during the last cycle were generally the shortest among the three values. These observations are consistent with training and cyclic effects observed in literature. For continuous, reliable strokes, an SMA spring actuator should, therefore, undergo cyclic loading prior to its implementation. With regards to the heating and cooling times, the first, median and end cycles did not tend to deviate from each other in a consistent pattern.

Divided further into seven subsections, one for each variable and a discussion on the internal stress and the deformation strain, this section presents and discusses the investigation's results.

\subsection{Wire Diameter}

Table 4 presents the wire diameter manipulation's results with respect to the averaged first, median and last value for each wire diameter. Figure $4 \mathrm{a}$ plots the wire diameter manipulation's averaged median heat and cooling times, while Figure $4 \mathrm{~b}$ plots the averaged strokes, martensite lengths and austenite lengths. Based on the heat and cooling time calculations performed using Equation 6 and 7, both reaction times were expected to increase in relation to an increased wire diameter, as the increase in volume leads to an increased thermal heat capacity; the experimental results generally supported this correlation. The first cycle generally produced the larger heat and cooling times, followed by the median and final cycles, but this pattern was not consistent for all wire diameter manipulations. It is therefore difficult to know if cycling had an effect on the reaction times.

Table 4. The averaged first, median and last values for the wire diameter manipulation.

\begin{tabular}{|c|c|c|c|c|c|c|c|c|c|c|c|c|c|c|c|}
\hline \multirow{2}{*}{$\begin{array}{c}\text { Wire } \\
\text { diameter } \\
(\mathbf{m m})\end{array}$} & \multicolumn{3}{|c|}{ Heat time (s) } & \multicolumn{3}{|c|}{ Cooling time (s) } & \multicolumn{3}{|c|}{$\begin{array}{c}\text { Martensite length } \\
\text { (mm) }\end{array}$} & \multicolumn{3}{|c|}{$\begin{array}{c}\text { Austenite length } \\
\text { (mm) }\end{array}$} & \multicolumn{3}{|c|}{ Stroke (mm) } \\
\hline & First & Med. & Last & First & Med. & Last & First & Med. & Last & First & Med. & Last & First & Med. & Last \\
\hline 0.145 & 4.3 & 2.8 & 2.3 & 3.2 & 3.1 & 3.3 & 178 & 178 & 177 & 134 & 145 & 147 & 44 & 33 & 30 \\
\hline 0.192 & 3.6 & 3.3 & 3.4 & 7.5 & 6.9 & 6.2 & 167 & 168 & 169 & 59 & 71 & 77 & 109 & 96 & 92 \\
\hline 0.248 & 6.9 & 6.3 & 7.1 & 11.9 & 12.7 & 11.3 & 128 & 132 & 129 & 28 & 30 & 30 & 100 & 102 & 99 \\
\hline 0.375 & 8.4 & 7.8 & 7.9 & 15.2 & 14.8 & 14.1 & 151 & 158 & 163 & 44 & 55 & 62 & 107 & 102 & 101 \\
\hline
\end{tabular}


Figure 4. Experimental results from the wire diameter manipulation. (a) (Left) The averaged median heat and cooling times. (b) (Right) The averaged median strokes, martensite lengths and austenite lengths.

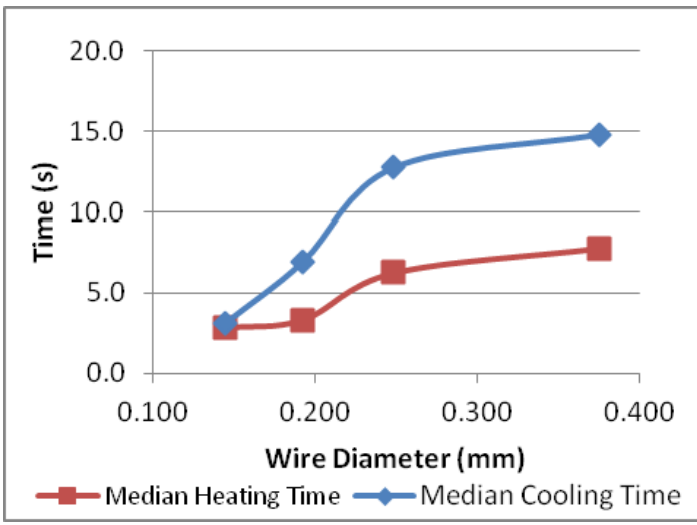

(a)

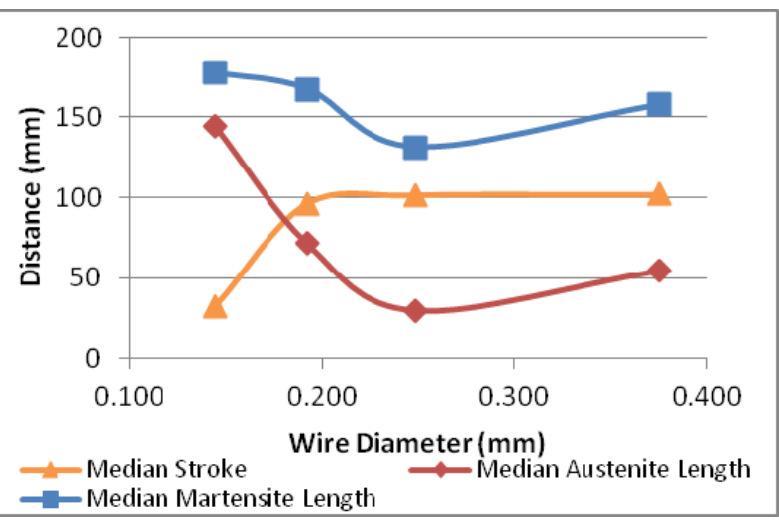

(b)

With regards to the stroke, had the change in moduli of rigidity been the only factor between phase transitions, the stroke would decrease with respect to an increasing diameter; this was not observed in the experimental results. When increasing the wire diameter from $0.145 \mathrm{~mm}$ to $0.192 \mathrm{~mm}$, the stroke nearly tripled from $33 \mathrm{~mm}$ to $96 \mathrm{~mm}$ before converging to a set stroke of $102 \mathrm{~mm}$ at subsequent wire diameter increases. The low stroke for the $0.15 \mathrm{~mm}$ wire diameter can be explained from its internal stress; ignoring the change in spring diameter, the maximum shear stress is estimated at a value of $823 \mathrm{MPa}$ : more than four-times the upper plateau stress found by An et al. [14]. The $0.145 \mathrm{~mm}$ wire diameter spring is thus forced to go beyond its recoverable shear strain limit, causing permanent deformation. The convergence to $102 \mathrm{~mm}$ could suggest that there is a limit to the amount of stroke that can be obtained for a helical SMA with respect to an increasing wire diameter. Alternatively, the converged value may actually be the peak of a plateau where the stroke may decrease at further wire diameter increases. As the wire diameter increases, the SMA spring's internal shear stress decreases, which could limit the amount of martensite that can be de-twinned by the bias force and, consequently, limit the stroke. Adding to the notion that permanent deformation occurred in the $0.15 \mathrm{~mm}$ to $0.20 \mathrm{~mm}$ wire diameter springs is the change in austenite length over subsequent cycles. Had no permanent deformation occurred, one would expect the austenite lengths to remain relatively constant throughout cycling. With the exception of the 0.25 wire diameter springs, there were observed increases in austenite lengths during cycling. Permanent strain was expected on the $0.15 \mathrm{~mm}$ and $0.20 \mathrm{~mm}$ wire diameters, as the estimated maximum internal shear stresses were $823 \mathrm{MPa}$ and $355 \mathrm{MPa}$, which are both well above the alloy's projected upper plateau stress of $183 \mathrm{MPa}$, but permanent strain was not expected for the $0.38 \mathrm{~mm}$ spring.

The increase in martensite and austenite lengths when comparing the $0.25 \mathrm{~mm}$ to $0.38 \mathrm{~mm}$ wire diameters was an interesting result. The austenite length was expected to further decrease for the associated increase in wire diameter as the estimated maximum shear stress decreased from $167 \mathrm{MPa}$ to $50.4 \mathrm{MPa}$. Decreasing to an internal stress below the $\tau_{\mathrm{f}}^{\mathrm{cr}}$ estimated by An et al. [14] should therefore not inhibit the transformation from taking place and not cause any permanent elastic strain in its austenite phase. As the $0.38 \mathrm{~mm}$ springs' austenite lengths did increase after subsequent cycles, plastic 
deformation had occurred. An explanation for this may lie in the SMA spring's preparation. When preparing the $0.38 \mathrm{~mm}$ wire diameter SMA spring, an increased amount of mechanical resistance was noticed when wrapping the annealed SMA wire around the steel rod. The other smaller wire diameters did not have this mechanical resistance, likely due to the fact that the wires were sufficiently small to solely deform via martensitic de-twinning. It is conceivable that the $0.38 \mathrm{~mm}$ spring may have surpassed its transformation strain when wrapped around the steel rod and, thus, may have further deformed via plastic deformation. This could explain the jump in austenite and martensite spring lengths. Remarkably, the jump in austenite spring length did not appear to influence the transformation stroke, as the martensite deflection accordingly increased to maintain the converged median stroke value of $102 \mathrm{~mm}$.

\subsection{Spring Diameter}

Table 5 presents the spring diameter manipulation's results with respect to the averaged first, median and last values obtained for each spring diameter. Figure 5a plots the spring diameter manipulation's averaged median heat and cooling times, while Figure $5 \mathrm{~b}$ plots the averaged median strokes, martensite lengths and austenite lengths.

Table 5. The averaged first, median and last values for the spring diameter manipulation.

\begin{tabular}{|c|c|c|c|c|c|c|c|c|c|c|c|c|c|c|c|}
\hline \multirow{2}{*}{$\begin{array}{c}\text { Inner } \\
\text { spring } \\
\text { diameter } \\
(\mathbf{m m}) \\
\end{array}$} & \multicolumn{3}{|c|}{ Heat time (s) } & \multicolumn{3}{|c|}{ Cooling time (s) } & \multicolumn{3}{|c|}{$\begin{array}{c}\text { Martensite length } \\
\text { (mm) }\end{array}$} & \multicolumn{3}{|c|}{$\begin{array}{l}\text { Austenite length } \\
\text { (mm) }\end{array}$} & \multicolumn{3}{|c|}{ Stroke (mm) } \\
\hline & First & Med. & Last & First & Med. & Last & First & Med. & Last & First & Med. & Last & First & Med. & Last \\
\hline 2.38 & 5.4 & 5.1 & 5. & 17.0 & 16 & 16.3 & 75 & 75 & 78 & 18 & 17 & 18 & 67 & 58 & 59 \\
\hline 3.175 & 6.9 & 6.3 & 7.1 & 11.9 & 12.7 & 11.3 & 128 & 132 & 129 & 28 & 30 & 30 & 100 & 102 & 99 \\
\hline 4.76 & 10.9 & 9.5 & 10.7 & 9.7 & 8.5 & 10.6 & 233 & 234 & 236 & 78 & 81 & 83 & 159 & 152 & 149 \\
\hline 6.35 & 10.3 & 9.3 & 8.6 & 9.0 & 10.6 & 10.6 & 314 & 318 & 319 & 146 & 159 & 167 & 173 & 158 & 151 \\
\hline
\end{tabular}

Figure 5. Experimental results from the spring diameter manipulation. (a) (Left) The averaged heat and cooling times. (b) (Right) The averaged strokes, martensite lengths and austenite lengths.

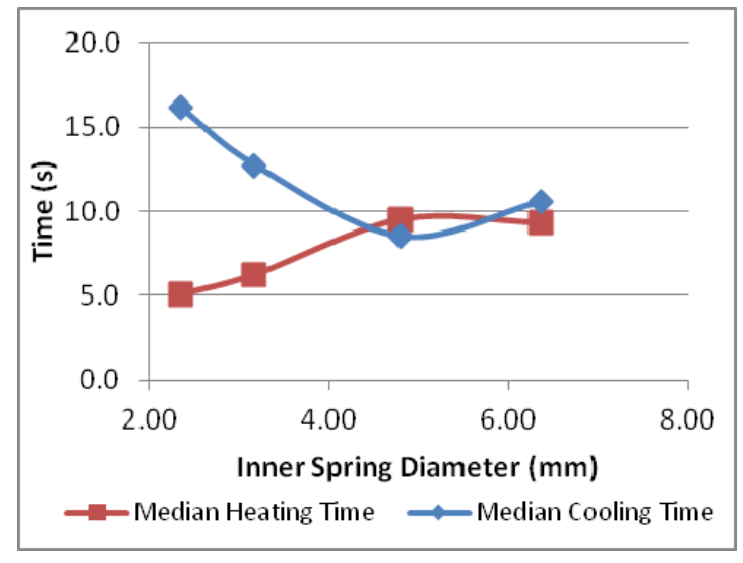

(a)

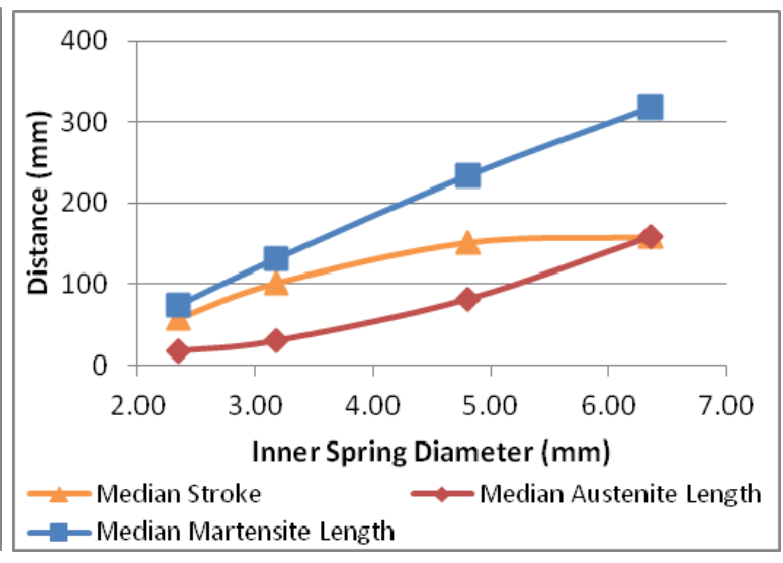

(b) 
For the reaction times, Equations 6 and 7 projected that the heat times and cooling times would respectively increase and decrease with an increasing spring diameter. Larger spring diameters have a larger internal stress; larger stresses in turn cause the transition temperatures to increase. More time is thus needed to reach the MA transition temperatures during heating, while less time is needed to reach the AM transition temperatures during cooling. This projection was observed in the experimental results. The smallest spring diameter spring $(2.34 \mathrm{~mm}$ inner diameter $)$ had the shortest averaged median heat time of $5.1 \mathrm{~s}$. The averaged median heat time would increase over two subsequent spring diameter increases before converging to a value of $9.3 \mathrm{~s}$ at the largest inner spring diameter of $6.36 \mathrm{~mm}$. A similar converging trend was observed for the cooling times. The smallest spring diameter had the largest averaged median cooling time of $16.1 \mathrm{~s}$ and decreased over two subsequent spring diameter increases. Interestingly, however, the averaged median cooling time increased over the final increase in spring diameter; springs with an inner spring diameter of $4.80 \mathrm{~mm}$ and $6.36 \mathrm{~mm}$ had values of $8.5 \mathrm{~s}$ and $10.6 \mathrm{~s}$, respectively. It is believed that permanent deformation may be responsible for this increase in cooling time.

Regarding the strokes as plotted on Figure 5b, like the wire diameter manipulation, the stroke increased as the inner spring diameter was increased, but converged to a set value; said value was $158 \mathrm{~mm}$. Also, like the wire diameter, this convergence is likely due to the increase in internal stress. As the inner spring diameter increased from $2.34 \mathrm{~mm}$, to $3.18 \mathrm{~mm}$, to $4.80 \mathrm{~mm}$ and to $6.36 \mathrm{~mm}$, the estimated maximum shear stress increased from $127 \mathrm{MPa}, 167 \mathrm{MPa}, 247 \mathrm{MPa}$ and $323 \mathrm{MPa}$. The last two spring diameters had maximum shear stresses that surpassed the alloy's upper plateau stress of $183 \mathrm{MPa}$, as estimated by An et al. [14]; permanent strain would therefore be expected and, thus, limit the maximum recoverable strain. Looking at the recorded cyclic effects in this investigation, the smaller spring diameters had little change in austenite length (less than $2 \mathrm{~mm}$ ), thus indicating that permanent strain minimally influenced the stroke. However, the larger two spring diameters had larger changes in austenite length; the $4.80 \mathrm{~mm}$ inner spring diameter had a $5 \mathrm{~mm}$ change in austenite length, while the $6.36 \mathrm{~mm}$ had more than four times the change in austenite length, with a value of $21 \mathrm{~mm}$. These results suggest that providing the upper plateau stress is surpassed, larger stresses will further decrease the overall stroke under cyclic loading due to permanent deformation.

With regards to the change in modulus of rigidity, the elastic stroke model projects that the stroke would continuously increase with an increasing diameter. The results suggest that the increasing elastic stroke and decreasing transformation stroke could be responsible for the converging stroke value; the observed convergence is likely that of a peak value where the summation of the elastic stroke and recoverable stroke has reached its maximum. Had larger spring diameters been investigated, the authors stipulate that strokes would continue to decrease, as said spring diameters would have larger internal stresses and, therefore, induce more permanent strain.

Another possible contribution to the converged values may be the decrease in spring diameter and increase in pitch angle during the low temperature, martensite phase. From the effective stroke and static two-state models presented in Section 2.2, a decrease in spring diameter and increase in pitch angle would in turn decrease the overall martensite deflection and stroke. 


\subsection{Bias Force}

Table 6 presents the bias force manipulation's results with respect to the averaged first, median and last value obtained for each bias force. Figure 6a plots the bias force manipulation's averaged median heat and cooling times, while Figure $6 \mathrm{~b}$ plots the averaged strokes, martensite lengths and austenite lengths.

Table 6. The averaged first, median and last values for the bias force manipulation.

\begin{tabular}{cccccccccccccccccc}
\hline $\begin{array}{c}\text { Bias } \\
\text { Force } \\
(\mathbf{N})\end{array}$ & \multicolumn{4}{c}{ Heat time (s) } & \multicolumn{4}{c}{ Cooling time (s) } & \multicolumn{3}{c}{$\begin{array}{c}\text { Martensite length } \\
(\mathbf{m m})\end{array}$} & \multicolumn{2}{c}{$\begin{array}{c}\text { Austenite length } \\
(\mathbf{m m})\end{array}$} & \multicolumn{3}{c}{ Stroke (mm) } \\
\hline & First & Med. & Last & First & Med. & Last & First & Med. & Last & First & Med. & Last & First & Med. & Last \\
\hline 0.196 & 6.4 & 4.9 & 4.9 & 18.3 & 18.5 & 16.7 & 103 & 103 & 105 & 21 & 22 & 22 & 82 & 81 & 83 \\
0.294 & 6.9 & 6.3 & 7.1 & 11.9 & 12.7 & 11.3 & 128 & 132 & 129 & 28 & 30 & 30 & 100 & 102 & 99 \\
0.392 & 10.2 & 8.6 & 8.8 & 10.8 & 10.9 & 11.0 & 137 & 140 & 142 & 34 & 39 & 41 & 103 & 101 & 101 \\
0.490 & 11.6 & 11.3 & 11.2 & 11.7 & 10.4 & 10.6 & 150 & 153 & 155 & 43 & 53 & 59 & 107 & 100 & 96 \\
\hline
\end{tabular}

Figure 6. Experimental results from the bias force manipulation. (a) (Left) The averaged heat and cooling times. (b) (Right) The averaged strokes, martensite lengths and austenite lengths.

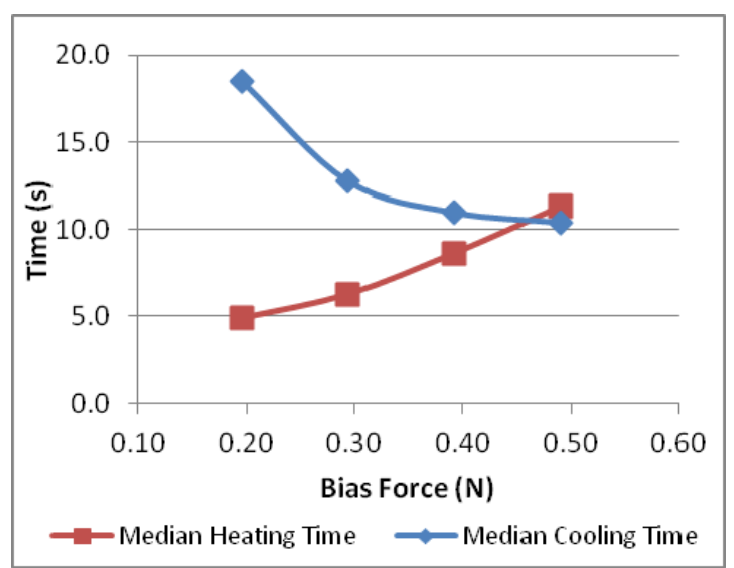

(a)

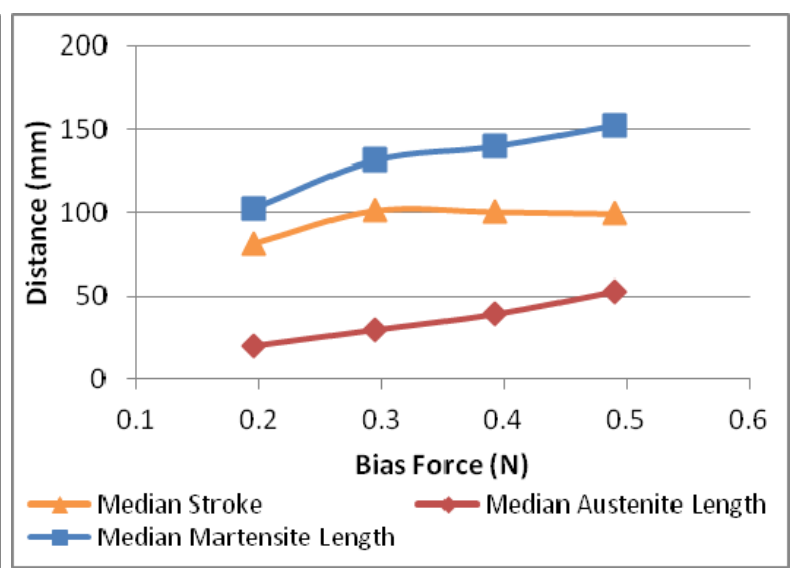

(b)

Based on the projections from Equations 4 and 5, it was anticipated that, with respect to an increasing bias force, the heat times and cooling times would increase and decrease, respectively. An increased bias force would induce a greater internal shear stress and, thus, increase the wire's transition temperatures throughout the wire's radius due to superelasticity. This projection was observed in the experimental results. For springs that were biased with $0.196 \mathrm{~N}, 0.294 \mathrm{~N}, 0.392 \mathrm{~N}$ or $0.490 \mathrm{~N}$, the averaged heat times were $18.5 \mathrm{~s}, 12.7 \mathrm{~s}, 10.9 \mathrm{~s}$ and $10.4 \mathrm{~s}$, respectively, while the averaged cooling times were $4.9 \mathrm{~s}, 6.3 \mathrm{~s}, 8.6 \mathrm{~s}$ and $11.3 \mathrm{~s}$. There were some differences in reaction times obtained in the first, median and last cycle, but the differences were not in a consistent pattern and, thus, do not support the notion that cycling has an effect on the reaction times.

The stroke increased from roughly $80 \mathrm{~mm}$ to $100 \mathrm{~mm}$ when the bias force increased from $0.196 \mathrm{~N}$ to $0.294 \mathrm{~N}$, but remained constant at around $100 \mathrm{~mm}$ on further bias force increases (up to $0.490 \mathrm{~N}$ ). Like the wire diameter and spring diameter manipulations, the stroke appears to converge to a set 
value. Also, like the wire diameter and spring diameter investigations, the cause of this convergence is likely due to the recoverable shear strain limit. At bias forces of $0.196 \mathrm{~N}, 0.294 \mathrm{~N}, 0.392 \mathrm{~N}$ and $0.490 \mathrm{~N}$, the projected maximum internal shear stresses are $111 \mathrm{MPa}, 167 \mathrm{MPa}, 223 \mathrm{MPa}$ and $278 \mathrm{MPa}$, respectively. Assuming that the alloy's upper plateau stress is the value estimated by An et al. [14], the maximum recover shear strain was surpassed for springs actuated with $0.392 \mathrm{~N}$ and 0.490 bias forces and, therefore, should cause permanent strain. If one looks at the cyclic changes in austenite length for all bias forces (i.e., the difference in the averaged first and last values), one would observe that there was relatively no change for the $0.196 \mathrm{~N}$ or $0.294 \mathrm{~N}$ bias forces $(1 \mathrm{~mm}$ and $2 \mathrm{~mm}$, respectively), but the austenite lengths did noticeably increase for the $0.392 \mathrm{~N}$ and $0.490 \mathrm{~N}$ bias forces ( $7 \mathrm{~mm}$ and $16 \mathrm{~mm}$ ). This suggests that the $0.392 \mathrm{~N}$ and $0.490 \mathrm{~N}$ did indeed succumb to some plastic deformation. Furthermore, the $0.490 \mathrm{~N}$ biased springs succumbed to more than twice the plastic deformation experienced by the $0.392 \mathrm{~N}$ biased springs, suggesting that the plastic deformation is greater for larger internal stresses. Additionally, the change in modulus of rigidity (i.e., the elastic stroke model presented in Section 2.2) suggests an increasing stroke with an increasing bias force. The combination of an increasing elastic stroke with an increase in permanent strain may be responsible for the stroke convergence observed in this investigation.

Like the spring diameter investigation, another contribution to the stroke convergence may be the decrease in spring diameter in the low temperature, martensite phase. At larger bias forces, the internal stress is greater and induces the martensite diameter to decrease and better disperse the stress. As already mentioned, the smaller martensite diameter would lead to a decreased elastic stroke, which in turn may have contributed to the stroke's convergence.

\subsection{Number of Active Turns}

Table 7 presents the number of active turns manipulation's results with respect to the averaged first, median and last value obtained for each turn amount. Figure $7 \mathrm{a}$ plots the number of active turns manipulation's averaged median heating and cooling times, while Figure $7 \mathrm{~b}$ plots the averaged strokes, martensite lengths and austenite lengths.

Table 7. The averaged first, median and last values for the number of active turns manipulation.

\begin{tabular}{|c|c|c|c|c|c|c|c|c|c|c|c|c|c|c|c|}
\hline \multirow{2}{*}{$\begin{array}{c}\text { Number } \\
\text { of active } \\
\text { turns }\end{array}$} & \multicolumn{3}{|c|}{ Heat time (s) } & \multicolumn{3}{|c|}{ Cooling time (s) } & \multicolumn{3}{|c|}{$\begin{array}{c}\text { Martensite length } \\
\text { (mm) }\end{array}$} & \multicolumn{3}{|c|}{$\begin{array}{c}\text { Austenite length } \\
(\mathrm{mm})\end{array}$} & \multicolumn{3}{|c|}{ Stroke (mm) } \\
\hline & First & Med. & Last & First & Med. & Last & First & Med. & Last & First & Med. & Last & First & Med. & Last \\
\hline 8 & 6.6 & 6.5 & 6.9 & 12.4 & 10.4 & 10.0 & 73 & 74 & 75 & 18 & 18 & 19 & 58 & 55 & 55 \\
\hline 12 & 6.3 & 6.1 & 6.6 & & 13.0 & 12.6 & 105 & 105 & 107 & 22 & 24 & 25 & 84 & 82 & 1 \\
\hline 16 & 6.9 & 6.3 & 7.1 & 11.9 & 12.7 & 11.3 & 128 & 132 & 129 & 28 & 30 & 30 & 100 & 102 & 99 \\
\hline 20 & 6.1 & 6.0 & 6.7 & 11.6 & 12.7 & 13.9 & 168 & 171 & 175 & 36 & 38 & 40 & 143 & 133 & 131 \\
\hline
\end{tabular}

As the number of spring turns is absent in the reaction time equations and does not influence a spring's internal stress, it was predicted that neither the heat times nor cooling times would change in relation to an increasing number of spring turns; the experimental results generally agreed with this prediction. With regards to the averaged median heat times, the values for all four spring turn values 
were all within $0.5 \mathrm{~s}$ of each other, while three out of the four cooling times were within $0.3 \mathrm{~s}$ of each other. The one exception was the smallest spring, the eight-turn spring, which had an averaged median heat time that was $2.4 \mathrm{~s}$ shorter than the average of the other spring turn values. One possible explanation for the eight-turn spring's smaller cooling time was the smaller stroke; the control system may have interpreted the bias mass as stationary, when in fact, the mass may still have been slowly moving. Another possible explanation may have been a larger conductive heat sink influence at the SMA spring's connections. With regards to cyclic effects, the heating times were generally consistent among the first, median and last cycles, suggesting that cycling does not affect the heat time. Although, there was some discrepancy among first, median and last cooling times, there does not appear to be a regular discrepancy pattern to indicate a correlation between cooling time and cyclic effects.

Figure 7. Experimental results from the number of active turns manipulation. (a) (Left) The averaged heat and cooling times. (b) (Right) The averaged strokes, martensite lengths and austenite lengths.

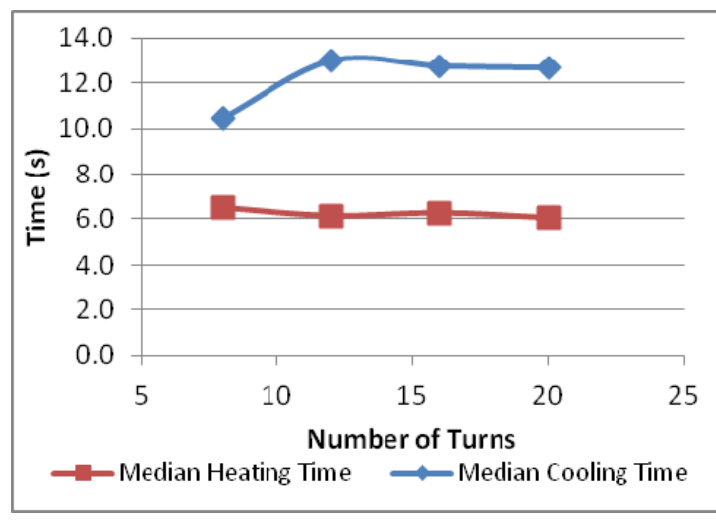

(a)

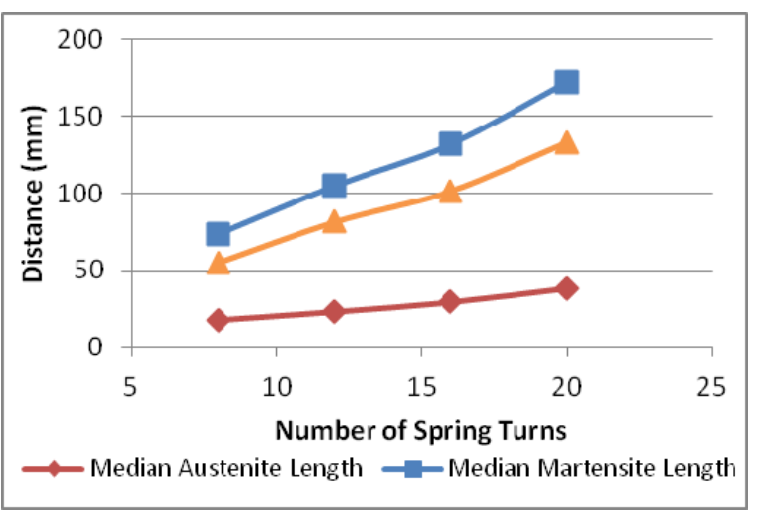

(b)

With reference to the stroke, it was predicted that not only the stroke would increase in relation to an increasing number of spring turns, but would linearly increase, as the number of spring turns theoretically have no relation to the overall stress and should therefore not influence the transformation strain. As the internal stress should be constant for all four spring turn manipulations, the transformation strain should therefore be constant for all four spring manipulations. Likewise, as all springs have the same bias force, wire diameter, spring diameter and moduli of rigidity, the elastic strain should also be the same value for all four spring turns. As predicted, the experimental stroke increased in a linear fashion. A linear regression was performed on the results with an $R^{2}$ value of 0.993; a linear relationship is thus probable. With regards to cyclic effects, there appears to be little discrepancy between the first, median and last stroke values, indicating that little or no permanent strain was present throughout the manipulation. As the estimated shear stress of $167 \mathrm{MPa}$ is less than the $183 \mathrm{MPa}$ upper plateau stress found by An et al. [14], it is conceivable that the springs did not suffer from any permanent strain. 


\subsection{Direct Current}

Table 8 presents the direct current manipulation's results with respect to the averaged first, median and last value obtained for each turn amount. Figure 8a plots the direct current manipulation's averaged median heat and cooling times, while Figure $8 \mathrm{~b}$ plots the averaged strokes, martensite lengths and austenite lengths.

Table 8. The averaged first, median and last values for the direct current manipulation.

\begin{tabular}{cccccccccccccccccc}
\hline $\begin{array}{c}\text { Direct } \\
\text { Current }\end{array}$ & \multicolumn{4}{c}{ Heat time (s) } & \multicolumn{4}{c}{ Cooling time (s) } & \multicolumn{4}{c}{$\begin{array}{c}\text { Martensite length } \\
(\mathbf{m m})\end{array}$} & \multicolumn{3}{c}{$\begin{array}{c}\text { Austenite length } \\
(\mathbf{m m})\end{array}$} & \multicolumn{3}{c}{ Stroke (mm) } \\
\cline { 2 - 3 } & First & Med. & Last & First & Med. & Last & First & Med. & Last & First & Med. & Last & First & Med. & Last \\
\hline 0.45 & 15.6 & 16.2 & 17.0 & 11.0 & 11.1 & 11.1 & 134 & 140 & 142 & 57 & 60 & 69 & 84 & 78 & 76 \\
0.50 & 10.5 & 9.5 & 11.0 & 10.9 & 11.4 & 10.8 & 132 & 132 & 136 & 29 & 32 & 34 & 114 & 100 & 96 \\
0.55 & 6.9 & 6.3 & 7.1 & 11.9 & 12.7 & 11.3 & 128 & 132 & 129 & 28 & 30 & 30 & 100 & 102 & 99 \\
0.60 & 6.7 & 4.7 & 4.9 & 12.6 & 11.0 & 11.8 & 126 & 127 & 133 & 24 & 28 & 29 & 111 & 99 & 100 \\
\hline
\end{tabular}

Figure 8. Experimental results from the direct current manipulation. (a) (Left) The averaged heat and cooling times. (b) (Right) The averaged strokes, martensite lengths and austenite lengths.

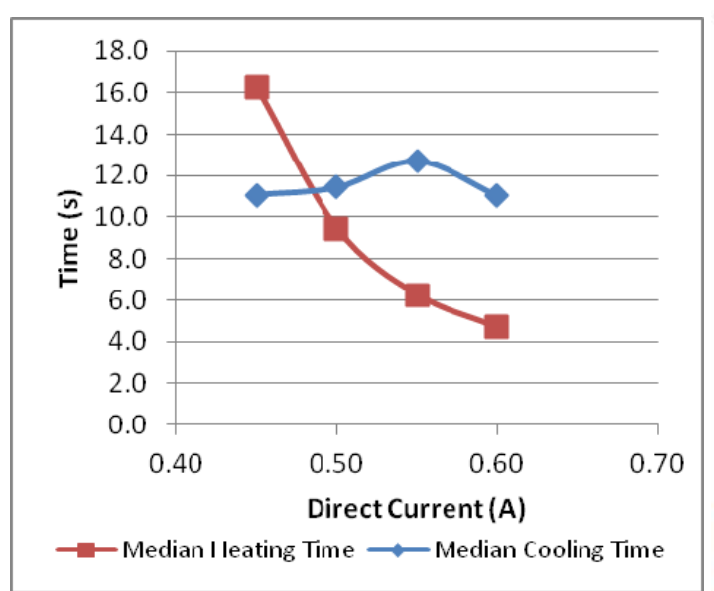

(a)

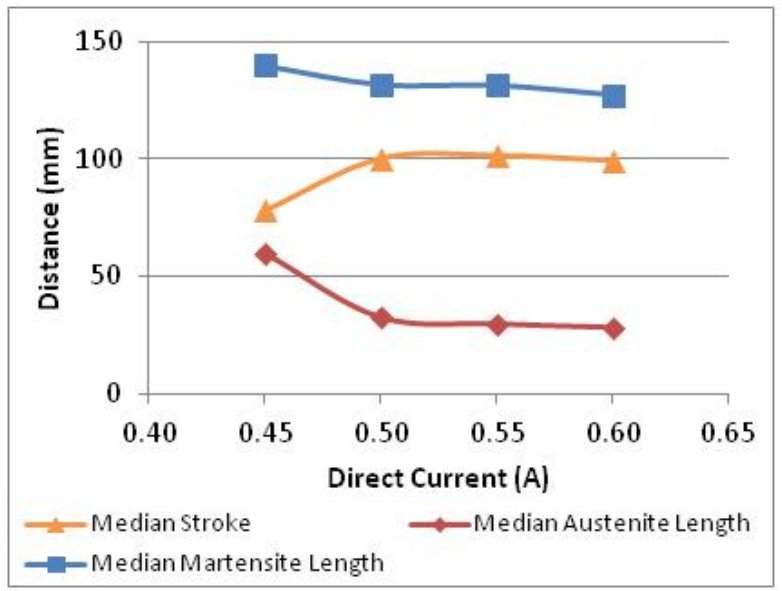

(b)

For the reaction times, with respect to an increasing direct current magnitude, it was predicted that the heat times would decrease due to the increase of thermal energy, while the cooling times would remain constant, as the transformation would stop at the same final temperature regardless of direct current magnitude. Both predicted patterns were generally correct. Using the averaged median values, the heat times comparatively decreased from $16.2 \mathrm{~s}$, to $9.5 \mathrm{~s}$, to $6.3 \mathrm{~s}$ and to $4.7 \mathrm{~s}$ for springs that were actuated with direct currents of $0.45 \mathrm{~A}, 0.50 \mathrm{~A}, 0.55 \mathrm{~A}$ and $0.60 \mathrm{~A}$, respectively, while the cooling times were all within 1-7 s of each other. Similar to the other investigations, the first, median and last reaction times showed some discrepancy with each other, but not in a consistent pattern to suggest that cycling affects the reaction times.

With regards to the strokes, it was anticipated that the strokes would be unaffected by a change in direct current, providing that the current is sufficient to induce the transformation. This prediction, 
overall, aligned with the experimental results, as the averaged median strokes for the springs actuated by $0.50 \mathrm{~A}, 0.55 \mathrm{~A}$ or $0.60 \mathrm{~A}$ were within $2 \%$ of each other with values around $100 \mathrm{~mm}$. However, the 0.45 A trials produced an averaged median stroke of $78 \mathrm{~mm}$. This can be attributed to the control system. During the 0.45 A trials, the bias mass often moved quite slowly during the transformation; the control system would sometimes mistake it for being stationary. At times, when the control system allowed a spring to fully transform at $0.45 \mathrm{~A}$, the stroke would generally be around $100 \mathrm{~mm}$, but the control system would often cut the true stroke short to as low as $40 \mathrm{~mm}$, because it was moving slowly. Had the control system allowed the spring to completely transform, the true median stroke value would likely have been around $100 \mathrm{~mm}$, like the other direct current magnitudes. Although there was some discrepancy between the first stroke and the median and last strokes for the springs activated by $0.50 \mathrm{~A}$ and $0.60 \mathrm{~A}$ direct currents, this pattern was not observed throughout all direct current magnitudes, thus not supporting that direct current influences permanent strain. As the direct current does not affect the static stress experienced by the SMA spring, it is expected that direct current does not influence permanent strain.

\subsection{Transition Temperature}

For the transition temperature manipulation, Table 9 presents the results with respect to the averaged first, median and last value. With respect to transition temperature, Figure 9a plots the averaged median heat and cooling times, while Figure $9 \mathrm{~b}$ plots the averaged strokes, martensite lengths and austenite lengths.

Table 9. The averaged first, median and last values for the springs with $90{ }^{\circ} \mathrm{C}$ austenitic starting temperature.

\begin{tabular}{|c|c|c|c|c|c|c|c|c|c|c|c|c|c|c|c|}
\hline \multirow[t]{2}{*}{$\mathbf{A}_{\mathrm{s}}$} & \multicolumn{3}{|c|}{ Heat time (s) } & \multicolumn{3}{|c|}{ Cooling time (s) } & \multicolumn{3}{|c|}{$\begin{array}{c}\text { Martensite length } \\
\text { (mm) }\end{array}$} & \multicolumn{3}{|c|}{$\begin{array}{c}\text { Austenite length } \\
\text { (mm) }\end{array}$} & \multicolumn{3}{|c|}{ Stroke (mm) } \\
\hline & First & Med. & Last & First & Med. & Last & First & Med. & Last & First & Med. & Last & First & Med. & Last \\
\hline $70^{\circ} \mathrm{C}$ & 6.9 & 6.3 & 7.1 & 11.9 & 12.7 & 11.3 & 128 & 132 & 129 & 28 & 30 & 30 & 100 & 102 & 99 \\
\hline $90^{\circ} \mathrm{C}$ & 7.9 & 5.8 & 5.9 & 7.3 & 6.4 & 6.4 & 167 & 175 & 177 & 70 & 107 & 118 & 64 & 67 & 58 \\
\hline
\end{tabular}

Figure 9. Experimental results from the transition temperature manipulation. (a) (Left) The averaged heat and cooling times. (b) (Right) The averaged strokes, martensite lengths and austenite lengths.

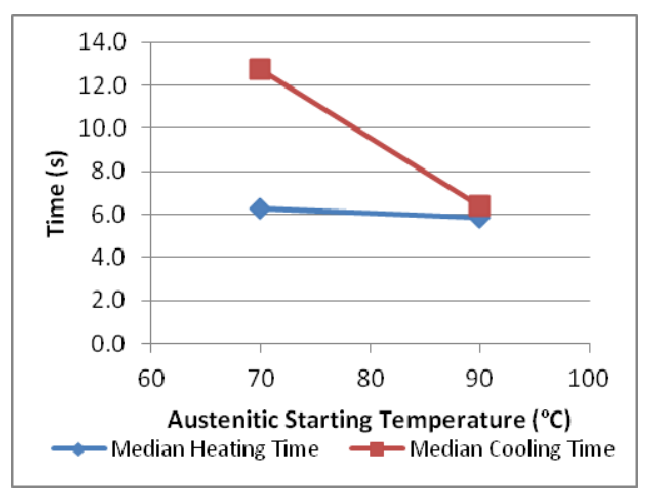

(a)

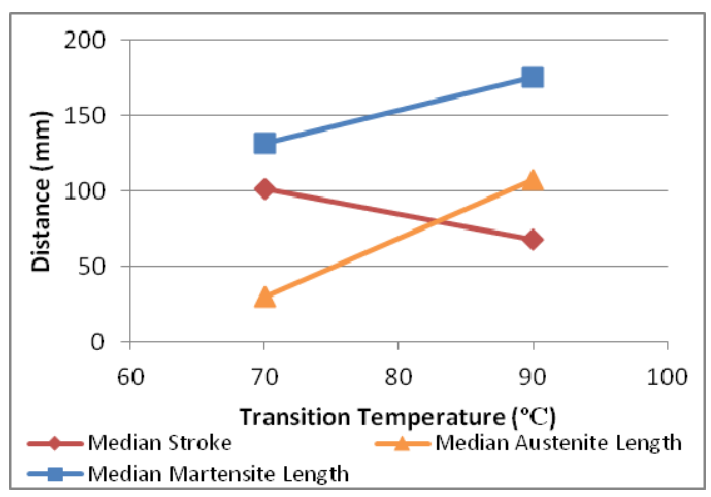

(b) 
With relation to reaction times, the derived heat transfer equations projected that the heat times and cooling times would respectively increase and decrease with an increased transition temperature; a higher transition temperature would require more time to attain when heated and require less time to attain when cooled. In terms of heating times, there was no observable difference between the $70{ }^{\circ} \mathrm{C}$ and $90{ }^{\circ} \mathrm{C}$ springs; the averaged median heat times were within $9 \%$ of each other. For the cooling times, the prediction was correct; taking approximately 50\% less time, the $90{ }^{\circ} \mathrm{C}$ SMA springs extended faster than their $70{ }^{\circ} \mathrm{C}$ counterparts. When analyzing the cyclic effects of the $90{ }^{\circ} \mathrm{C}$ SMA springs, the heat and cooling times obtained from the first cycle were both larger than their last and median counterparts, which were within $2 \%$ of each other. This suggests that cycling did affect the reaction times for the $90{ }^{\circ} \mathrm{C}$ SMA springs.

It was perceived that the stroke would not change in relation to the transition temperature, as the transition temperature is absent from any of the models presented in Section 2.2. In opposition of said projection, the experimental results demonstrated that the transition temperature does have an influence on the stroke. When comparing the $90{ }^{\circ} \mathrm{C}$ SMA springs to their $70{ }^{\circ} \mathrm{C}$ counterparts, the strokes decreased by $34 \%$. When comparing the changes in austenite length through cycling, the $90{ }^{\circ} \mathrm{C}$ SMA springs had a $69 \%$ increase from first and last austenite lengths, while the $70{ }^{\circ} \mathrm{C}$ SMA springs only had a $7.1 \%$ increase. Not only did the stroke decrease, but the $90{ }^{\circ} \mathrm{C}$ SMA springs suffered more from fatigue under cyclic loading. Evidently, the $90{ }^{\circ} \mathrm{C}$ is not as strong as the $70{ }^{\circ} \mathrm{C}$ wire. This may be due to different additives in the $90{ }^{\circ} \mathrm{C}$ wire that were added by the manufacturer to increase its transition temperature at the expense of the SMAs strength; however, the literature shows that additives are more likely to strengthen a material rather than weaken it [27,29]. A more plausible explanation is that the $90{ }^{\circ} \mathrm{C}$ SMA wires were aged on purpose by the manufacturer to increase the transition temperature. Aging will increase the transition temperature, but at the expense of its strength properties, including its upper plateau strength [11,16,17,27]. A decreased upper plateau strength would in turn decrease the maximum transformation strain, which correlates with the experimental results.

\subsection{Transformation Strain vs. Maximum Shear Stress}

The results from the investigations suggested a correlation between stroke and internal stress. The stress needs to be large enough to exploit the recoverable transformation stroke, i.e., the recoverable de-twinning of martensite, but if the maximum shear stress surpasses a critical amount, permanent strain will develop and impede the total stroke. The results suggest that a combination of elastic strain, i.e., the change in modulus of rigidity, and the recoverable transformation strain contribute to the overall stroke. Using the shear strain formula with respect to deflection (i.e., $\gamma=(\delta d) /\left(\pi D_{m}^{2} n\right)$ ), the shear strain associated with the averaged median stroke was found and plotted with reference to the approximated maximum shear stress (i.e., $\tau_{\max }=\left(8 F D_{m}\right) /\left(\pi d^{3}\right)$ ) (see Figure 10). The stroke shear strain appears to peak around the alloy's upper plateau stress of $183 \mathrm{MPa}$ [14], suggesting that the stroke can be maximized at this critical stress value. However, the peak was not observed for the wire diameter investigation, as the largest wire diameter of $0.38 \mathrm{~mm}$ produced the largest stroke strain at an estimated maximum shear stress of 50.4 MPa. As mentioned in Section 4.1, the authors attribute this increase in stroke to the preparation of the SMA springs with $0.38 \mathrm{~mm}$ wire diameter. 
Figure 10. The approximate stroke shear strain vs. approximate maximum shear stress.

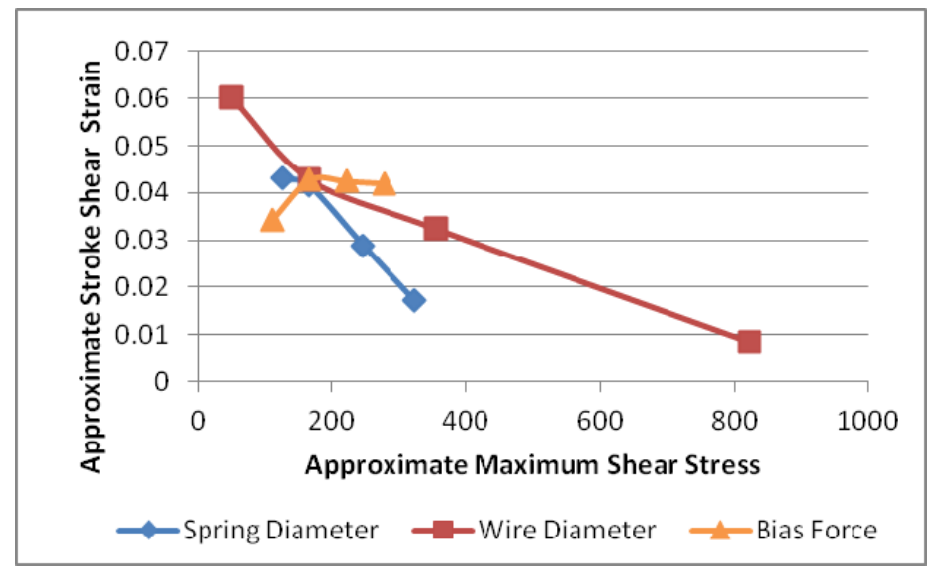

\section{Conclusions}

Recalling the first objective, it was desired to find correlations between a SMA spring's parameters and their dynamic response. This investigation successfully tested how six variables (i.e., wire diameter, spring diameter, bias force, number of active spring turns, direct current magnitude and transition temperature) independently affect the performance of SMA actuators in relation to their reaction times and strokes. It was found that four out of six variables affect the heating time, four out of six variables affect the cooling time and all six variables affect the stroke. These experimental results will provide helical SMA actuator designers a better understanding of how each parameter affects the actuator's resultant reaction times and strokes. Recalling the second objective, the study also aimed to observe how cycling affects a helical spring's reaction times and strokes.

Throughout this investigation, there have been some common behavioural patterns among a helical spring's mechanical output. For the heat times (i.e., elapsed time for a MA transformation), it was found that the patterns projected by the derived heat transfer equation that accounted for superelasticity (Equation 6) were generally correct (the exception being the transition temperature investigation), but greatly underestimated the true heat times. This was expected, as the equation does not take into account the work being exercised by the helical SMA actuator. However, for the cooling times (i.e., the elapsed time for an AM transformation), the patterns projected by the derived heat transfer equation (Equation 7) were not only generally correct, but most values were within $10 \%$ of the experimental values, indicating that it can provide a good estimate of the true reaction time. However, it is reiterated that the derived equation is generalized, and some properties used in the calculations were estimated, not found. Nonetheless, the overall results support that superelasticity cannot be overlooked when predicting a helical SMAs reaction times. Overall, cycling did not show any consistent changes in heat times or cooling times. Although there was variation in reaction times regarding the first, median and last values, the variation was not consistent to suggest that cycling alters the reaction times. The only investigation that did show consistent variation was the transition temperature investigation; it is speculated that this occurred due to the different material properties of the $90{ }^{\circ} \mathrm{C}$ SMA wire.

The investigation supported that internal stress influences the stroke. For the investigations that involved increases or decreases in shear stress; i.e., the wire diameter, spring diameter and bias force 
investigations; a common theme of stroke convergence was observed. Based on permanent strain as observed by cyclic changes in austenite lengths, it is stipulated that this convergence is actually a peak, where the combined effects of modulus of rigidity change and martensitic de-twinning have reached a maximum. It is believed that this maximum value occurs at the upper plateau stress, as the maximum strain occurred at a maximum shear stress of around $183 \mathrm{MPa}$ : the alloy's upper plateau stress as found by An et al. [14]. This notion is further supported from the number of active spring turns manipulation; the stroke positively correlated with the number of spring turns in a linear fashion. The internal stress was constant for all four turn manipulations, thus indicating a constant transformation strain. Likewise, the elastic strain (i.e., the strain responsible from the change in modulus of rigidity) is also independent of the number of turns; the overall stroke should therefore positively correlate in a linear manner with the amount of turns; this was realized in the experimental results, thus supporting that the stroke is dependent on internal stress. It was also mentioned that the decrease in spring diameter in the low temperature, martensite phase may have also contributed to the converging values. When succumbed to cycling, it was found that the stroke decreased due to permanent strain, i.e., training. The stroke decrease was more extensive at larger internal stresses, where permanent strain is more prevalent. For continuous use, one should sufficiently train the helical SMA actuator prior to its implementation.

The third objective was to catalogue the stroke and reaction times at different spring parameters for reference. As helical SMA actuators are not completely understood mechanically, it is often necessary to experimentally test their dynamic response, as opposed to using theory to predict their behaviour. Additionally, custom made helical SMA actuators can be quite expensive in comparison to readily available SMA wire. The catalogue made from these experimental results will not only enable helical SMA actuator designers to choose appropriate parameters for projects that require certain reaction times or strokes, but will also allow them to use readily available, cost-effective SMA wire to produce the helical SMA actuators, as opposed to buying them custom made. However, the catalogue is limited by the springs' preparation, i.e., an annealing temperature and time of $500{ }^{\circ} \mathrm{C}$ and $10 \mathrm{~min}$, respectively. Different annealing temperatures and times could lead to different reaction times and strokes. It should also be emphasized that the trends discovered in this investigation only apply to a specific set of controlled parameters, as a controlled experiment approach was used in this investigation. It is conceivable that, had a different set of controlled parameters been used, the trends may have been different due to interactions between certain variables. To determine if the observed trends are universal, it would be recommended to perform a factorial design to further this investigation.

\section{Acknowledgments}

This work was supported by the Atlantic Innovation Fund from the Atlantic Canada Opportunities Agency (ACOA) and by NSERC: Natural Sciences and Engineering Research Council of Canada (for A.L. Kalamkarov).

\section{Conflict of Interest}

The authors declare no conflict of interest. 


\section{References}

1. Spaggiari, A.; Dragoni, E. Multiphysics modeling and design of shape memory alloy wave springs as linear actuators. J. Mech. Des. 2011, 133, 151-159.

2. Beesley, P. Hylozoic Ground; Riverside Architectural Press: Toronto, ON, Canada, 2010.

3. Spinella, I.; Dragoni, E. Analysis and design of hollow helical springs for shape memory actuators. J. Intell. Mater. Syst. Struct. 2010, 6, 185-199.

4. Liang, C.; Rogers, C.A. One-dimensional thermomechanical constitutive relations for shape memory materials. J. Intell. Mater. Syst. Struct. 1990, 2, 207-234.

5. Baz, A.; Iman, K.; Mccoy, J. The dynamics of helical shape memory actuators. J. Intell. Mater. Syst. Struct. 1990, 1, 105-133.

6. Liang, C.; Rogers, C.A. Design of shape memory alloy actuators. J. Intell. Mater. Syst. Struct. 1997, 8, 303-313.

7. Liang, C.; Rogers, C.A. Design of shape memory alloy springs with applications in vibration control. J. Intell. Mater. Syst. Struct. 1997, 8, 314-322.

8. Lee, H.J.; Lee, J.J. Evaluation of the characteristics of a shape memory alloy spring actuator. Smart Mater. Struct. 2000, 9, 817-823.

9. Huang, W. On the selection of shape memory alloys for actuators. Mater. Eng. 2002, 23, 11-19.

10. Jee, K.K.; Han, J.H.; Kim, Y.B.; Lee, D.H.; Jang, W.Y. New method for improving properties of SMA coil springs. Eur. Phys. J. Spec. Top. 2008, 158, 261-266.

11. Kim, S.; Hawkes, E.; Cho, K.; Jolda, M.; Foley, J.; Wood, R. Micro Artifical Muscle Fiber Using NiTi Spring for Soft Robotics. In Proceedings of the 2009 IEEE/RSJ International Conference on Intelligent Robots and Systems, St. Louis, MO, USA, 2009.

12. Stebner, A.; Padula III, S.; Noebe, R.; Lerch, B., Quinn, D. Development, characterization, and design considerations of $\mathrm{Ni}_{19.5} \mathrm{Ti}_{50.5} \mathrm{Pd}_{25} \mathrm{Pt}_{5}$ high-temperature shape memory alloy helical actuators. J. Intell. Mater. Syst. Struct. 2009, 20, 2107-2126.

13. Aguiar, R.A.A.; Savi, M.A.; Pachecho, P.M.C.L. Experimental and numerical investigations of shape memory alloy helical springs. Smart Mater. Struct. 2010, 19, 025008.

14. An, S.-M.; Ryu, J.; Cho, M.; Cho, K.-J. Engineering design framework for a shape memory alloy coil spring actuator using a static two-state model. Smart Mater. Struct. 2010, 21, 055009.

15. Spaggiari, A.; Spinella, I.; Dragoni, E. Design equations for binary shape memory actuators under arbitrary external forces. J. Intell. Mater. Syst. Struct. 2012, doi:10.1177/1045389X12444491.

16. Pelton, A.R.; DiCello, J.; Miyazaki, S. Optimisation of processing and properties of medical grade Nitinol wire. Minim. Invasive Ther. Allied Technol. 2000, 9, 107-118.

17. Liu, X.; Wang, Y.; Yang, D.; Qi, M. The effect of ageing treatment on shape-setting and superelasticity of a nitinol stent. Mater. Charact. 2008, 59, 402-406.

18. Yoon, S.H.; Yeo, D.J. Experimental investigation of thermo-mechanical behaviors in Ni-Ti shape memory alloy. J. Intell. Mater. Syst. Struct. 2008, 19, 283-289.

19. Yates, S. Structural and Smart Materials Analysis in Responsive Architectural and Textile Mechanical Applications. M.A.Sc. Thesis, Dalhousie University, Halifax, NS, Canada, 2012, pp. 316-409. 
20. Bonnemaison, S.; Berzowska, J.; Macy, C.; Muller, R. @LAB Architextile Laboratory: Electronic textiles in architecture; TUNS Press: Halifax, NS, Canada, 2011.

21. Follador, M.; Cianchetti, M.; Arienti, A.; Laschi, C. A general method for the design and fabrication of shape memory alloy active spring actuators. Smart Mater. Struct. 2012, 21, 115029.

22. Khan, E.; Srinivasan, S.M. A new approach to the design of helical shape memory alloy spring actuators. Smart Mater.Res. 2011, 2011, 1-5.

23. Hartl, D.J.; Lagoudas, D.C. Thermomechanical Characterization of Shape Memory Alloy Materials. In Shape Memory Alloys: Modelling and Engineering Applications; Lagoudas. D.C., Ed.; Springer Science + Business Media, LLC: New York, NY, USA, 2008; pp. 53-119.

24. Reynaerts, D.; van Brussel, H. Design aspects of shape memory actuators. Mechatronics 1998, 8, 635-656.

25. Mirzaeifar, R.; DesRoches, R.; Yavari, A. Exact solutions for pure torsion of shape memory alloy circular bars. Mech. Mater. 2010, 42, 797-806.

26. Stevens, C.G. Designing shape memory alloy springs for linear actuators. Springs 1999, 38, 24-34.

27. Pelton, A.R.; Russel, S.M.; DiCello, J. The physical metallurgy of nitinol medical applications. J. Metall. 2003, 33-37.

28. Technical Characteristics of FLEXINOL ${ }^{\circledR}$ Actuator Wires. Available online: http://www.dynalloy.com/TechSheets.php (accessed on 17 November 2011).

29. Kumar, P.K.; Lagoudas, D.C. Introduction to Shape Memory Alloys. In Shape Memory Alloys: Modelling and Engineering Applications; Lagoudas. D.C., Ed.; Springer Science + Business Media, LLC: New York, NY, USA, 2008; pp. 1-51.

(C) 2013 by the authors; licensee MDPI, Basel, Switzerland. This article is an open access article distributed under the terms and conditions of the Creative Commons Attribution license (http://creativecommons.org/licenses/by/3.0/). 